Mechanical Systems and Signal Processing

Accepted for publication - Nov. 2011

\title{
Modeling and validation of Off-Road Vehicle Ride Dynamics
}

\author{
Alireza Pazooki ${ }^{a^{*}}$, Subhash Rakheja ${ }^{\mathrm{a}}$ and Dongpu Cao ${ }^{\mathrm{b}}$ \\ ${ }^{a}$ CONCAVE Research Centre, Concordia University, Montreal, Canada \\ ${ }^{\mathrm{b}}$ Department of Engineering, Lancaster University, Lancaster, UK \\ E-mails: a.r.pazooki@gmail.com; rakheja@alcor.concordia.ca; d.cao@lancaster.ac.uk \\ "Corresponding author.
}

\begin{abstract}
Increasing concerns on human driver comfort/health and emerging demands on suspension systems for off-road vehicles call for an effective and efficient off-road vehicle ride dynamics model. This study devotes both analytical and experimental efforts in developing a comprehensive off-road vehicle ride dynamics model. A three-dimensional tire model is formulated to characterize tire-terrain interactions along all the three translational axes. The random roughness properties of the two parallel tracks of terrain profiles are further synthesized considering equivalent undeformable terrain and a coherence function between the two tracks. The terrain roughness model, derived from the field-measured responses of a conventional forestry skidder, was considered for the synthesis. The simulation results of the suspended and unsuspended vehicle models are derived in terms of acceleration PSD, and weighted and unweighted rms acceleration along the different axes at the diver seat location. Comparisons of the model responses with the measured data revealed that the proposed model can yield reasonably good predictions of the ride responses along the translational as well as rotational axes for both the conventional and suspended vehicles. The developed off-road vehicle ride dynamics model could serve as an effective and efficient tool for predicting vehicle ride vibrations, to seek designs of primary and secondary suspensions, and to evaluate the roles of various operating conditions.
\end{abstract}

Keywords: Off-road vehicle ride dynamics, ride dynamics model, model validation, suspension design, three dimensional tire-terrain interaction model, terrain roughness characterization.

\section{Introduction}

Ride dynamics of ground vehicles has been extensively explored in the last few decades, where the fundamentals of vehicle ride vibrations along with various types of suspension systems have been well developed [1-4]. In parallel, the understanding of human body vibrations and human perception of vehicle vibrations has also been considerably improved, contributing the further enhancement in vehicle ride vibration isolations and driver/passengers comfort and health [5-7]. However, the documented literature suggested a large majority of these efforts made on the road vehicle ride dynamics and suspension systems, while only small efforts have been devoted to those of the off-road vehicles. This may be attributed mainly to two factors: (a) It has generally been accepted that the knowledge and suspension systems developed for road vehicles can be adapted to off-road vehicles with moderate modifications; and (b) the significant difficulty in characterizing/modeling tire-terrain interactions (for either deformable or undeformable terrains). 
Unlike road vehicles, off-road vehicles are known to transmit higher magnitudes of low frequency whole-body vibration (WBV) along the translational as well as rotational axes to the drivers, which can be attributed to vehicle interactions with uneven off-road terrains, and lack of adequate primary and/or secondary suspensions. A number of epidemiological studies have shown that prolonged occupational exposure to such WBV is directly associated with various health and safety risks among the vehicle drivers [8,9]. It has been reported in different fieldbased studies, e.g. [10,11], that WBV exposure of many off-road vehicles may exceed the health-caution guidance zone and the exposure limit defined in ISO-2631-1 [5] and EN14253 [12], respectively.

The field-based studies together with the guidelines are vital for estimating risk of musculoskeletal disorders among the occupational drivers but provide only limited data for designs of preventive measures involving primary and secondary suspension, tires and operating conditions. It has been shown that the WBV environment of off-road vehicles strongly depends upon a number of design and operating factors such as vehicle weight and dimensions, vehicle load, task, primary and secondary suspension systems, terrain roughness and driving speed [4, 13, 14]. Tiemessen et al. [13] evaluated the effectiveness of evidence-based preventive strategies to reduce WBV exposure using 37 different field and laboratory studies, and concluded that the dynamic characteristics of the vehicle need to be considered for design of effective strategies, apart from the driver skill and behavior. Rehn et al. [14] studied the variations in WBV exposure of 11 drivers of 7 forwarders operating on 10 different terrains in terms of vibration dose value (VDV), and showed that VDV was strongly dependent upon forwarder model, terrain type, operating load and the driver.

The most popular preventive measure of WBV exposure reduction has been the suspension at the seat, which limits only vertical vibration [15-17]. A suspension seat, however, yields limited isolation of high intensity vertical vibration encountered in many off-road vehicles, which may in-part be attributed to lack of suspension tuning with regard to the intensity and frequency contents of the target vehicle vibration [17]. A number of studies have also explored different cab suspension designs $[18,19]$. These suspensions, however, are not effective in limiting the transmission of fore-aft and lateral vibration, whose magnitudes are known to be either comparable to or exceed that of the vertical vibration [10, 20]. In addition, performance of secondary suspensions, generally derived from subsystem models of the seat and cab suspensions [16-20], may be also limited due to lack of consideration of dynamics of the target vehicle [13]. Although axle suspensions offer greater potential to reduce translational as well as rotational vibrations, relatively fewer studies have attempted design and performance analyses of such suspensions, where the enhancements in ride have been clearly demonstrated [21-26]. This may in-part be attributed to design challenges associated with conflicting requirements posed by the ride and roll stability measures, and wide variations in the axle loads. Anti-roll suspension concepts with a ride-height leveling function, such as interconnected hydro-pneumatic suspensions [4, 27, 28], would offer a very promising alternative solution for off-road vehicle applications.

Similar to those in analyses of the road vehicle ride dynamics and suspension designs, the reported off-road vehicle ride dynamics models used for suspension designs, generally, employ either linear or nonlinear point-contact tire models that are known to be computationally 
efficient. Such tire models, however, cannot capture the tire-terrain interaction properties in the shear axes and thus the fore-aft and lateral ride vibration responses [26]. Furthermore, the pointcontact tire models tend to overestimate contact pressure and wheel hop [29]. The study [26] demonstrated that using one-dimensional point-contact tire model would also overestimate the vertical acceleration responses. In addition, coupling of the pitch and roll modes with longitudinal and lateral dynamics, respectively, cannot be reasonably represented. Considering that off-road vehicles exhibit substantial lateral and longitudinal vibrations attributed to coupled vehicle vibration modes and horizontal tire-road interactions, it is essential to develop and integrate more efficient tire models capable of predicting multi-axis tire forces.

Although comprehensive finite element tire models have been widely reported for characterizing multi-axis tire-terrain interactions [30], such models could find only limited applications in ride dynamic analysis of vehicles due to associated complexities and high computational demands. Crolla et al. [31] proposed a three-dimensional point-contact tire model to account for horizontal and vertical tire forces in an off-road tractor model in a highly efficient manner. The model, however, does not account for the finite tire foot print and the contributions due to local gradient of the terrain, and the wheel-hop. Tire models with radial visco-elastic elements and adaptive contact patch have also been employed to determine the tire-terrain forces along the vertical and longitudinal axis $[32,33]$.

In this study, a comprehensive off-road ride dynamics model is derived with integrating a threedimensional tire model, which can be conveniently used for evaluating suspension design concepts. The three-dimensional tire-terrain interaction model is formulated based on the adaptive radial representation of the tires in the pitch plane together with a lateral dynamic model based on the side-slip theory and the tire-lag. The ride dynamic responses of the model are evaluated under excitations representing an equivalent undeformable forestry terrain, and compared with the field measured data to demonstrate the model validity. The ride responses are obtained for the vehicle model with and without a rear-axle suspension to further illustrate the ride performance potentials of the torsio-elastic suspension.

\section{Modeling of Tire-Terrain Interactions}

The tire-terrain interactions along the three translational axes are characterized through formulation of a three-dimensional tire model considering undeformable terrain. The proposed model integrates an adaptive footprint tire model for describing the vertical and longitudinal forces developed by the tire, and a visco-elastic lateral model based on the side-slip theory.

\subsection{Adaptive Footprint Tire Model in the Pitch-Plane}

Figure 1 illustrates an adaptive footprint model based on the concept of continuous radial spring representation of the tire [34], which permits computation of the net contact patch, $P_{1} P_{2}$, in the pitch plane and the resulting tire forces along the vertical and longitudinal axis. The resultant force developed at the tire-terrain interface is evaluated by considering the tire as a continuous ring of radial springs uniformly distributed over contact patch, $P_{1} P_{2}$, which varies with the local terrain profile. The dissipative property of the tire is represented by a lumped viscous damper, as shown in the Figure. Assuming that the tire-terrain contact $\left(P_{1} P_{2}\right)$ represents the idealized deflection of the tire, the resultant force $F_{w n}$, assumed to act normal to the footprint force, is 
obtained through integration of the normal components of the elemental radial forces over the footprint [32], such that:

\section{FIGURE 1 about here}

$$
F_{w n}=2 K R_{w}\left[\sin \alpha_{w}-\alpha_{w} \cos \alpha_{w}\right]+F_{d w}
$$

where $K$ is the linear stiffness constant of the radial element, $R_{w}$ is undeformed tire radius and where $\alpha_{w}$ is one-half of the wheel-terrain contact patch angle, as shown in Fig. 2(a). $F_{d w}=C \dot{r}_{w}$ is the tire damping force, where $C$ is the viscous damping coefficient and $\dot{r}_{w}$ is the relative velocity across the damping element which relates to the vertical motion of the wheel centre, the terrain elevation at the center of the contact patch, and the gradient of the terrain profile, such that:

\section{FIGURE 2 about here}

$\dot{r}_{w}=\left(\dot{z}_{w c}-\dot{z}_{0}\right) \cos \gamma$

where $\dot{z}_{w c}$ is the vertical velocity of the wheel center, $\dot{z}_{0}=U \tan \gamma$ is the terrain imposed vertical velocity at the mid-point of the idealized tire-terrain contact patch $P_{1} P_{2}, \gamma$ is the gradient of the instantaneous contact patch, and $U$ is the constant forward speed.

The radial spring constant of the tire is estimated from Eq.(1) and the static tire deflection $\delta_{s t}$ subject to a static load, $W$, on a flat surface, as shown in Fig. 1(b), such that:

$$
K=\frac{W}{2 R_{w}\left[\sin \alpha_{w}-\alpha_{w s} \cos \alpha_{w}\right]}
$$

The determination of the resultant tire force from Eq. (1) necessitates the instantaneous contact patch angle $2 \alpha_{w}$ and thus the instantaneous patch length $P_{1} P_{2}$. The coordinates of $P_{1}$ and $P_{2}$ are derived from the circle-line interaction representation [34], shown in Fig. 2(b). The algorithm initially identifies all the terrain elevation points $P_{s}$ that lie within the projection of the wheel on the terrain surface, $X_{w c}-R_{w} \leq X_{P s} \leq X_{w c}+R_{w}$, where $X_{P s}$ are the $x$-coordinates of the identified terrain points, and $X_{w c}$ is $x$-coordinate of the wheel center. The elevation points within the wheel geometry are subsequently identified using the criteria: $\left(Z_{w c}-Z_{P_{S}}\right)^{2}+\left(X_{w c}-X_{P_{S}}\right)^{2}<R_{w}^{2}$, where $Z_{w c}$ and $Z_{P s}$ are the vertical coordinates of the wheel center and terrain contact point, respectively. The coordinates of the two extreme elevation points, $P_{L}$ and $P_{R}$, within the wheel geometry together with those of the preceding $\left(P_{L-1}\right)$ and following $\left(P_{R+1}\right)$ points are used to define the equations of the lines intersecting the tire ring at $P_{1}$ and $P_{2}$, respectively, as shown in Fig. 2(b). The coordinates of the intersection points, $\left(X_{1}, Z_{1}\right)$ and $\left(X_{2}, Z_{2}\right)$, are finally determined from the equations of the two lines and that of the tire ring, given by: $\left(X_{w c}-X\right)^{2}+\left(Z_{w c}-Z\right)^{2}=R_{w}^{2}$. 
The instantaneous contact patch angle $\alpha_{\mathrm{w}}$ can be derived from the angular coordinates $\theta_{1}$ and $\theta_{2}$ of the intersection points $P_{1}$ and $P_{2}$, respectively, as seen in Fig. 2(a), such that $2 \alpha_{w}=\theta_{2}-\theta_{1}$. Using the circle-line interaction method, these can be expressed as:

$\theta_{1}=\tan ^{-1}\left[\frac{Z_{1}-Z_{w c}}{x_{1}-X_{w c}}\right] ; \quad \theta_{2}=\tan ^{-1}\left[\frac{Z_{2}-Z_{w c}}{X_{2}-X_{w c}}\right] ;$

Furthermore, the gradient of the instantaneous contact patch can be computed from $\gamma=\theta_{1}+\alpha_{w}-1.5 \pi$. The vertical and longitudinal forces developed by the tire can be derived from Eq. (1) using the instantaneous contact patch angle and gradient of the idealized contact patch, such that:

$$
F_{T z}=F_{w n} \cos \gamma ; \quad F_{T x}=F_{w n} \sin \gamma
$$

where $F_{T x}$ and $F_{T z}$ are the resultant longitudinal and vertical tire forces, respectively.

\subsection{Lateral Tire Force}

A lateral tire force model [31] based on the side-slip theory could be applied to account for contributions of the lateral tire-terrain interaction to the ride dynamics of off-road vehicles. The lateral tire force model may be integrated with the adaptive footprint tire model in order to describe the tire-terrain interactions along the three translational axes. Furthermore, the large and soft tires, popularly employed in off-road vehicles, exhibit considerable hysteresis and appreciable time lag associated with buildup of lateral force. It has been further shown that the lateral force developed by a tire can be derived considering first-order tire dynamics, where the time constant directly relates to the relaxation length $\sigma$ and the forward speed $U$ [35]. Assuming small slip angle and a constant vertical load, the tire lateral force can be related to the side-slip angle $\alpha$ and tire cornering stiffness $C_{\alpha}$ in the following manner:

$$
\tau \dot{F}_{y}(t)+F_{y}(t)=C_{\alpha} \alpha(t)
$$

where the time constant $\tau=\sigma / U, F_{y}(t)$ is the lateral force developed by the tire and $C_{\alpha} \alpha(t)$ is the steady-state lateral force developed by the tire.

The reported lateral tire force model is integrated with the pitch-plane adaptive foot-print model, as shown in Fig. 3, to derive the tire forces along the three translational axes. In the absence of the external input $\left(u_{y}=0\right)$, the tire lateral force can be related to the stiffness and damping coefficients in the following manner:

\section{FIGURE 3 about here}

$$
\frac{C_{T y}}{K_{T y}} \dot{F}_{y}(t)+F_{y}(t)=C_{T y} \dot{y}(t)
$$


where $C_{T y}$ and $K_{T y}$ are damping and stiffness coefficients of the model, which are related to cornering stiffness and relaxation length of the tire, such that: $C_{T y}=C_{\alpha} / U$ and $K_{T y}=C_{\alpha} / \sigma$, and $\dot{y}(t)=U \alpha(t)$ is the lateral velocity developed at the tire-terrain contact.

\section{Ride Dynamics Modeling of Off-Road Vehicles \\ 3.1 Unsuspended Off-Road Vehicles}

Assuming negligible contributions of the articulation mechanism to the vehicle responses, a 5 degree-of-freedom (DOF) ride dynamic model of an un-suspended off-road skidder is developed, which is an extension of the pitch-plane model presented in [26]. Figures 4(a) and 4(b) illustrate the model in the pitch and roll-planes, respectively. The forward speed is assumed to be constant, the axles are considered to be rigidly attached to the vehicle frame, and axles, frame and the cabin are considered as a rigid mass supported on four tires. The tire forces are derived using the adaptive foot-print and lateral force tire model described above. The equations of motion for the vehicle model are derived considering differential terrain excitations at the two tire tracks:

\section{FIGURE 4 about here}

$$
\begin{aligned}
& m_{s} \ddot{z}_{s}+\sum_{1}^{4} F_{T z i}=0 ; \quad m_{s} \ddot{x}_{s}+\sum_{1}^{4} F_{T x i}=0 ; \quad m_{s} \ddot{y}_{s}+\sum_{1}^{4} F_{T y i}=0 ; \\
& I_{y y s} \ddot{\theta}_{s}-W B_{1}\left[F_{T z 1}+F_{T z 2}\right]+W B_{2}\left[F_{T z 3}+F_{T z 4}\right]-H\left[\sum_{i=1}^{4} F_{T x i}\right]=0 ; \\
& I_{x x s} \ddot{s}_{s}-T\left[F_{T z 1}+F_{T z 3}\right]+T\left[F_{T z 2}+F_{T z 4}\right]+H\left[\sum_{i=1}^{4} F_{T y i}\right]=0
\end{aligned}
$$

where $z_{s}, x_{s}, y_{s}, \theta_{s}$, and $\varphi_{s}$ are the vertical, longitudinal, lateral, pitch and roll deflections, respectively, of the sprung mass $m_{s}$ about its static equilibrium. $I_{x x s}$ and $I_{y y s}$ are roll and pitch mass moments of inertia of the sprung mass, respectively. The vertical $\left(F_{T z i}\right)$, lateral $\left(F_{T y i}\right)$ and longitudinal $\left(F_{T x i}\right)$ tire forces developed by tire $i(i=1,2$ for front axle tires and $i=3,4$ for the rear axle tires), are derived from the tire models expressed in Eqs. (5) and (7). The lateral force $\left(F_{T y i}\right)$ where lateral velocity $\dot{y}_{i}$ of the contact point is given by $\dot{y}_{i}=\dot{y}_{s}+H \dot{\varphi}_{s}(i=1, . ., 4) . W B_{1}, W B_{2}, T$, and $H$ are the geometric parameters shown in Fig. 4.

\subsection{Suspended Off-Road Vehicles with Rear-Axle Torsio-Elastic Suspension}

A torsio-elastic axle suspension concept has been proposed to improve the terrain-induced ride vibrations of a forestry skidder, while providing high effective roll stiffness [26]. The ride performance potential was demonstrated through field measurements and analysis of a vehicle model with a point-contact tire model. In this study, the conventional skidder retrofitted with the torsio-elastic suspension at the rear-axle is modeled considering multi-axis tire-terrain interactions, as shown in Figs. 5(a) and 5(b). The detailed linkage model is also shown in Fig. 5(c). The vehicle with the rear-axle suspension is modeled as a 14-DOF dynamic system, which includes: 5-DOF of the sprung mass $m_{s}^{\prime}$ comprising chassis, cab, front axle and the mounted equipment $\left(x_{s}, y_{s}, z_{s}, \varphi_{s}, \theta_{s}\right)$; 3-DOF of the real axle unsprung mass $\left(y_{u r}, z_{u r}, \varphi_{u r}\right)$; and 3-DOF of each of the two suspension units $\left(y_{i}, z_{i}, \varphi_{i} ; i=3,4\right)$. The equations of motion for the sprung and 
rear-axle unsprung masses of the vehicle subject to terrain excitations at the right- and left-tracks are formulated as:

\section{FIGURE 5 about here}

$$
\begin{aligned}
& m_{s}^{\prime} \ddot{z}_{s}+\sum_{i=1}^{2} F_{T z i}+\sum_{i=3}^{4}\left(F_{z i}\right)=0 ; \quad m_{s}^{\prime} \ddot{y}_{s}+\sum_{i=3}^{4} F_{y i}+\sum_{i=1}^{2} F_{T y i}=0 ; \quad M \ddot{x}_{s}+\sum_{i=1}^{4} F_{T x i}=0 \\
& I_{X X S}^{\prime} \ddot{\varphi}_{s}+M_{\varphi 4 s}+M_{\varphi 3 s}+\left(F_{z 4}-F_{z 3}\right) L_{1}+\sum_{i=3}^{4} F_{y i} h+T\left(F_{T z 2}-F_{T z 1}\right)+\sum_{i=1}^{2} F_{T y i}(H)=0 \\
& I_{Y Y S}^{\prime} \ddot{\theta}_{s}+\sum_{i=3}^{4} F_{z i} W B_{2}-\sum_{i=1}^{2} F_{T z i} W B_{1}-H\left(\sum_{i=1}^{4} F_{T x i}\right)=0 \\
& m_{u r} \ddot{z}_{u r}+\sum_{i=3}^{4} F_{T z i}-\sum_{i=3}^{4} F_{z i u}=0 ; \\
& I_{r} \ddot{\varphi}_{u r}+\left(F_{T z 4}-F_{T z 3}\right) T+\sum_{i=3}^{4}\left[R F_{T y i}+F_{y i u} h_{1}\right]+\left(F_{z 3 u}-F_{z 4 u}\right)\left(L_{1}+L_{0}\right)-M_{\varphi 3 u}-M_{\varphi 4 u}=0 \\
& m_{i} \ddot{z}_{i}+F_{z i u}-F_{z i}=0 ; \quad m_{i} \ddot{y}_{i}+F_{y i u}-F_{y i}^{4} F_{y i u}+\sum_{i=3}^{4} F_{T y i}=0 ; \\
& I_{i} \ddot{\varphi}_{i}-\left(F_{z i u}+F_{z i}\right) \frac{L_{0}}{2}-M_{\varphi i s}+M_{\varphi i u}=0 ; \quad i=3,4
\end{aligned}
$$

In the above equations, the vertical and lateral forces, and roll moment due to rear axle suspension are denoted by $F_{z i}, F_{y i}$ and $M_{\varphi i s}(i=3,4)$, respectively, which are derived from the detailed linkage model, shown in Fig. 5(c). These have been developed in [26] considering 3DOF of each of the rear axle suspension links, including vertical $\left(z_{u r}\right)$, lateral $\left(y_{u r}\right)$ and roll $\left(\varphi_{u r}\right)$ of the unsprung mass, and lateral, vertical and roll $\left(y_{i}, z_{i}\right.$ and $\left.\varphi_{i} ; i=3,4\right)$ motions of the suspension linkages. The geometric parameters $L_{0}, L_{1}, R_{w}, h$, and $h_{1}$ are illustrated in Fig. 6 . The vertical, longitudinal and lateral tire forces are derived from Eqs. (5) and (6), while the lateral velocity of the footprint of the rear axle tires, however, is related to the unsprung mass motion such that: $\dot{y}_{i}=\dot{y}_{u r}+R_{w} \dot{\varphi}_{u r}(i=3,4)$.

\subsection{Estimation of the Terrain Roughness Profiles}

The roughness of a deformable off-road terrains have been expressed by a power regression function in spatial spectral density $G_{z}(\Omega)$ representing the elevation of an equivalent undeformable terrain. The regression function for a forestry terrain, derived from the field measured responses of a conventional unsuspended forestry skidder, has been expressed as [26]:

$$
G_{Z}(\Omega)=\alpha \Omega^{-\beta} ; \quad \alpha>0 \text { and } \beta>0
$$

where $\Omega$ is the spatial frequency that is related to forward speed $U$ and the temporal frequency $f$, such that $f=\Omega U$, and constants $\alpha$ and $\beta$ are the roughness coefficients and wavinesses of the terrain, respectively. The constants $\alpha$ and $\beta$ which were identified from the measured vertical, 
pitch and roll ride responses of the conventional unsuspended vehicle through solution of an error minimization problem described in [26]. Compared to the other reported profiles like plowed field, pasture and the MVEE [36, 37], the identified roughness model showed lower roughness particularly at the lower wave numbers, which was in part be attributed to the soft terrain since the measurements were performed late in the fall season.

The spatial power spectral density (PSD) of the terrain roughness may also be expressed by a rational PSD function in temporal frequency $\omega$ and operating speed $U$ [38]:

$T(\omega)=\left(\frac{\mu_{4}}{\pi}\right)\left[\frac{\mu_{4} U}{\mu_{1}^{2} U+\omega^{2}}\right]+\left(\frac{\mu_{5}}{\pi}\right)\left[\frac{\mu_{2} U\left(\mu_{2}^{2} U^{2}+\mu_{3}^{2} U^{2}+\omega^{2}\right)}{\left(\mu_{2}^{2} U^{2}-\mu_{3}^{2} U^{2}+\omega^{2}\right)^{2}+4 \mu_{2}^{2} \mu_{3}^{2} U^{2}}\right]$

where $\mu_{i}(i=1, \ldots, 5)$ are constant coefficients that were identified from the terrain profile spectrum over a range of 5 to $25 \mathrm{~km} / \mathrm{h}$ forward speed, as: $\left(0.19,2.00,0.76,2.00 \times 10^{-1}, 3.00 \times 10^{-}\right.$ $\left.{ }^{3}\right)$. The comparison of the spatial PSD derived from the above function with that derived from Eq. (11) in Fig. 6 shows that $T(\omega)$ can accurately describe the identified terrain spectra.

\section{FIGURE 6 about here}

The above function permits the synthesis of time-history of the terrain roughness by applying a random white noise signal of unity power. For this purpose, the spectral density function in Eq. (12) is expressed as:

$T(\omega)=b_{1}\left[\frac{\omega^{4}+b_{2} \omega^{2}+b_{0}^{2}}{\left(\omega^{2}+a_{1}^{2}\right)\left(\omega^{4}+a_{2} \omega^{2}+a_{0}^{2}\right)}\right]$

where $a_{i}$ and $b_{i}(i=0,1,2)$ are functions of the vehicle speed and coefficients $\mu_{i}$, which can be applied to describe the random road irregularity $z_{0}(t)$ through stationary solution of a third-order differential equation subject to a random white-noise input of unity power $l(t)$ in the following manner [38]:

$$
\begin{aligned}
& \dddot{z}_{0}(t)+\left(a_{1}+\sqrt{a_{2}+2 a_{0}}\right) \ddot{z}_{0}(t)+\left(a_{0}+a_{1} \sqrt{a_{2}+2 a_{0}}\right) \dot{z}_{0}(t)+a_{0} a_{1} z_{0}(t)= \\
& \sqrt{b_{1}}\left[\ddot{l}(t)+\left(\sqrt{b_{2}+2 b_{0}}\right) \dot{l}(t)+b_{0} l(t)\right]
\end{aligned}
$$

The above differential equation has been derived from a frequency response function $H(\omega)$ obtained from Eq. (13) based on the stationary random process [39] in the following manner:

$$
H(\omega)=\sqrt{b_{1}}\left[\frac{-\omega^{2}+\sqrt{\left(b_{2}+2 b_{0}\right)} i \omega+b_{0}}{\left(i \omega+a_{1}\right)\left(-\omega^{2}+\sqrt{\left(a_{2}+2 a_{0}\right)} i \omega+a_{0}\right)}\right]=\frac{Z_{0}(\omega)}{l(\omega)}
$$

where $Z_{0}(\omega)$ and $l(\omega)$ are the corresponding finite Fourier transforms of $z_{0}(t)$ and $l(t)$, respectively. 
$z_{0}(t)$ can be considered to represent average roughness profile of the terrain, assuming that the terrain tracks are statistically equivalent. In off-road operations, the two vehicle tracks are invariably subjected to different terrain elevations that contribute to the roll and lateral dynamic responses of the vehicle. The roughness profiles of the two tracks may be estimated by assuming a coherence function describing the linear dependence of two random profiles. A few studies have established coherence functions of roughness profiles of two tracks of the roadways. The analyses of measured road profiles by Bogsjo [40] showed that roughness profiles of the two tracks are highly correlated at low frequencies, while the coherence diminishes at higher frequencies. Yonglin and Jiafan [41] described the coherence by a piecewise linear function in frequency of the form:

$$
\gamma_{L R}^{2}(\omega)=\left\{\begin{array}{cc}
1-0.9\left(\frac{\omega}{2 \pi}\right) & ; \omega \leq \omega_{1} \\
0.1 & ; \omega>\omega_{1}
\end{array}\right.
$$

where $\gamma_{L R}^{2}(\omega)$ is the coherence between the left and right tracks of a roadway and $\omega_{1}$ is the transition frequency, which was taken as $2 \mathrm{~Hz}$ for the roadways. Considering that off-road terrains exhibit relatively low frequency components, a lower transition frequency would be more reasonable, which is considered as $1 \mathrm{~Hz}$ in this study that is identical to the measured predominant roll frequency of the forestry vehicle [26]. The above coherence function can also be expressed accurately by a second-order function of the form:

$$
\left|H_{1}(\omega)\right|^{2}=\left[\frac{e_{2}^{2} \omega^{4}+\left(e_{1}^{2}-2 e_{2} e_{0}\right) \omega^{2}+e_{0}^{2}}{d_{2}^{2} \omega^{4}+\left(d_{1}^{2}-2 d_{2} d_{0}\right) \omega^{2}+d_{0}^{2}}\right]=\gamma_{L R}^{2}(\omega)
$$

where $e_{i}$ and $d_{i}(i=0,1,2)$ are constant coefficients that are identified from the coherence function as: $(4.47,0.73,-0.06$; and $4.47,1.81,-0.20)$. The validity of the above function in describing the coherence is illustrated through comparison of the coherence values derived from Eqs. (15) and (17), as shown in Fig. 7.

\section{FIGURE 7 about here}

Roughness profiles of the two tracks may be synthesized by considering the above coherence function and two uncorrelated random white noise signals, $l(t)$ and $n(t)$, applied to the spectral density function of the road profile. Assuming that Eq. (14) describes the roughness profile of the left track $z_{0 L}(t)$, the roughness of the right track may be derived by considering a filtered random process $r(t)$, such that:

$r(t)=h_{1}(t) l(t)+h_{2}(t) n(t)$

where $h_{1}(t)$ is the coherence function and $h_{2}(t)$, describes the uncorrelated component of $r(t)$, which can be expressed as [39]: 


$$
\left\{\begin{array}{l}
\left|H_{1}(\omega)\right|^{2}=\gamma_{L R}^{2}(\omega) \\
\left|H_{2}(\omega)\right|^{2}=1-\gamma_{L R}^{2}(\omega)
\end{array}\right.
$$

As it is shown in Fig. 8 schematically, the functions $h_{1}(t)$ and $h_{2}(t)$ are applied to obtain the filtered random process $r(t)$. The terrain roughness function $h(t)$, described in Eq. (15) is subsequently applied to $r(t)$ to obtain random road irregularity of the right track $Z_{O R}(t)$ through stationary solution of Eq. (14).

\section{FIGURE 8 about here}

Figures 9(a) and 9(b) illustrate time histories of the roughness of the left and right tracks considering a forward speed of $5 \mathrm{~km} / \mathrm{h}$, respectively. Figure 10 illustrates the coherence of the two random terrain profiles, which is compared with the assumed target coherence. The time history of roll excitation attributed to roughness of the two tracks is further computed considering vehicle track width of $2.5 \mathrm{~m}$. Figures 11(a) and 11(b) illustrate the time-history and PSD of the roll displacement, respectively. The results show that the coherence of the two tracks roughness is quite close to the assumed target coherence, while the peak roll displacement excitation approaches 6 degrees.

\section{FIGURE 9 about here}

FIGURE 10 about here

\section{FIGURE 11 about here}

\subsection{Method of Analysis}

The unsuspended and suspended vehicle models together with the three-dimensional tire model are analyzed considering terrain excitations arising from two parallel tracks, shown in Fig. 9, at a constant forward speed. The simulations were initially performed at a speed of $5 \mathrm{~km} / \mathrm{h}$ in order examine model validity on the basis of the field-measured data that were acquired at the same speed. The simulation parameters of the vehicle models are summarized in Table 1 [26]. The model responses were evaluated in terms of PSD of translational and rotational accelerations, and frequency-weighted and un-weighted rms accelerations at the operator seat location. The vertical, longitudinal, and lateral acceleration responses at the seat location were derived from the following relations:

\section{TABLE 1 about here}

$$
\ddot{z}_{\text {seat }}=\ddot{z}_{s}-l_{x} \ddot{\theta}_{s} ; \quad \ddot{x}_{\text {seat }}=\ddot{x}_{s}+h^{\prime} \ddot{\theta}_{s} ; \quad \ddot{y}_{\text {seat }}=\ddot{y}_{s}-h^{\prime} \ddot{\phi}_{s}
$$

where $h^{\prime}$ and $l_{x}$ are the vertical and longitudinal distances of the seat, respectively, from the sprung mass $c g$. The frequency-weighted accelerations were obtained using the weighting functions defined in ISO-2631-1 [5]. For this purpose, the response time-histories were analyzed 
to derive PSD and rms spectra using the modified Welch method [42] together with Hanning window and $50 \%$ overlap of the data segments. The total WBV exposure was also derived in terms of vibration total value, $a_{v}$ :

$$
a_{v}=\sqrt{\left(k_{x}^{2} a_{w x}^{2}+k_{y}^{2} a_{w y}^{2}+a_{w z}^{2}\right)}
$$

where $k_{x}$ and $k_{y}$ are the additional weightings factors imposed on the weighted longitudinal and lateral acceleration values, as described in ISO-2631-1 [5]. $a_{w x}, a_{w y}$ and $a_{w z}$ are frequencyweighted longitudinal, lateral and vertical rms accelerations at the seat, respectively. The eighthour energy equivalent frequency-weighted acceleration $A(8)$ is also computed for a daily exposure duration of $T_{e}=4$ hours, based on the information attained from the Forestry Engineering Research Institute of Canada [43], such that $A(8)=a_{v} \sqrt{T_{e} / T_{0}}$, where $T_{0}$ is the reference duration of 8 hours.

\section{Results Discussions and Model Validation}

The validity of the vehicle models was examined on the basis of the field measured responses of a conventional skidder and a skidder integrated with a torsio-elastic rear suspension. The measurements and analysis of the field data have been described in [26]. The study [26] further showed that addition of the torsio-elastic suspension to the rear unit resulted in substantial reductions in overall unweighted and frequency-weighted rms accelerations measured near the operator seat. In this study the field-measured responses are used to examine validity of the vehicle models with three-dimensional tire model.

The acceleration PSD response spectra obtained along the vertical, fore-aft, lateral, pitch and roll axes at the operator seat location, derived assuming negligible effects of the seat cushion, are compared with the measured spectra in Figs. 12 and 13 for the conventional and suspended vehicles models, respectively. The results show respectively good agreements between the models and the measured data for both the models. The results suggest that the proposed threedimensional tire model provides more accurate predictions of ride responses along all the axes compared to the results obtained with a one-dimensional point-contact tire model reported in [26].

\section{FIGURE 12 about here}

\section{FIGURE 13 about here}

The results show peak responses near 1 and $2 \mathrm{~Hz}$, which are attributed to pitch and vertical mode resonances of the vehicle models. The predominant longitudinal vibration of the sprung mass occurs at a frequency slightly above $1 \mathrm{~Hz}$ for both the vehicle models, which is partly associated with its coupling with the pitch mode. The roll and lateral acceleration responses also show two peaks near $0.9 \mathrm{~Hz}$ and above $2.5 \mathrm{~Hz}$ denoting the roll and lateral mode resonance frequencies of the sprung mass suggesting the coupling between lateral and roll modes.

While the results suggest reasonably good agreements between the model responses and the measured spectra, some deviations are also evident. As it is observed in Figs. 12 and 13, the 
lateral and roll responses of the both suspended and unsuspended vehicle models at frequencies range above $3 \mathrm{~Hz}$ are slightly below the measured data, which may partially be attributed to the relatively low roll excitation due to synthesized terrain profiles for the two parallel tracks at higher frequencies. The longitudinal acceleration response magnitudes of the unsuspended vehicle model are lower than the measured magnitudes at frequencies below $2 \mathrm{~Hz}$. The longitudinal response of the suspended vehicle, however, is greater than the measured response at frequencies below $2 \mathrm{~Hz}$.

The deviations in the response are also believed to be caused by various simplifying modeling assumptions, particularly the consideration of negligible contributions due to articulation forces and moments, constant forward speed, absence of wheel hop, and linear suspension properties. Despite the observed deviations, the results suggest that the vehicle models with the threedimensional tire model can predict the ride dynamic responses along the vertical, longitudinal, lateral, roll and pitch axes, reasonably well. The models can thus severe as an effective tool to seek desirable suspension design parameters and to assess the whole-body vibration exposure of the operator.

The overall frequency-weighted and unweighted rms acceleration values of the model responses are further computed and compared with those derived from the measured data in Tables 2 and 3. The frequency weighting $W_{d}, W_{k}$ and $W_{e}$ are applied to derive the overall frequency weighted rms acceleration along the horizontal $(x, y)$, vertical $(z)$ and rotational $(\theta, \varphi)$ axis, as recommended in ISO-2631-1 [5].

\section{TABLE 2 about here}

\section{TABLE 3 about here}

The results suggest good agreements between the rms acceleration values of both the models and the measured data particularly for the bounce and pitch rms acceleration responses. Slightly higher deviations, however, are observed in the lateral and longitudinal acceleration values of the unsuspended vehicle model. Similar deviations are also evident in the longitudinal rms acceleration of the suspended vehicle model, which are partly attributed to the simplifying assumptions of the models, specially the lack of consideration of the articulation force and moments. It should be noted that the previous study [26] using a one-dimensional point-contact tire model demonstrated considerable overestimates in the bounce-mode acceleration (for suspended vehicle: $28 \%$ deviation for unweighted rms acceleration and $58 \%$ deviation for weighted rms acceleration.) However, the off-road vehicle ride dynamics model developed in this study shows a considerable improvement in the bounce-mode acceleration, where deviations less than 5\% were observed in Tables 3.

The tables also present the vibration total value, $a_{v}$, derived from Eq. (22), and $A(8)$ values estimated from models responses and measured data. These illustrate deviations in the order of $10-11 \%$ between the model and measured responses. Comparisons of the results presented in Tables 2 and 3 confirm that the addition of a rear-axle torsio-elastic suspension yields significant reduction in the WBV exposure of the operator along all the translational axes. Both the total value and eight-hour energy equivalent frequency-weighted acceleration are nearly $38 \%$ lower 
for the suspended vehicle compared to the unsuspended vehicle. The results further show that the $A(8)$ value of the unsuspended vehicle exceeds the "limiting value" of $1.15 \mathrm{~m} / \mathrm{s}^{2}$ defined in the EC guidelines [12]. While the suspended vehicle yields substantially lower $A(8)$ value, its magnitude still exceeds the "action value" of $0.5 \mathrm{~m} / \mathrm{s}^{2}$ defined in the EC guidelines.

\section{Parameter Sensitivity Analysis}

Different vehicle design and operating parameters including the torsio-elastic suspension properties, the linkage geometry, vehicle forward speed, vehicle load, and terrain roughness would affect the ride performance potential of the torsio-elastic suspension. Among these, the suspension characteristics would also influence the load carrying capacity of the vehicle. The validated suspended vehicle model is used to study the sensitivity of ride responses to variations in the suspension parameters so as to seek desirable suspension design parameters. The analyses are performed for the unloaded vehicle operating at a constant forward speed of $5 \mathrm{~km} / \mathrm{h}$. The suspension design parameters considered include: the stiffness $\left(k_{y}, k_{z}, k_{t}\right)$ and damping $\left(c_{y}, c_{z}, c_{t}\right)$ constants, and the linkage length $\left(L_{0}\right)$ of the rear-axle torsio-elastic suspension. The stiffness and

damping constant was varied by $\pm 50 \%$ about the nominal value, and the variation in the link

length was limited to $\pm 25 \%$, while the vehicle track width was held constant. The responses

were obtained in terms of unweighted and frequency-weighted vertical, longitudinal, lateral, pitch and roll rms accelerations, which are summarized in Table 4.

\section{TABLE 4 about here}

The results revealed considerable influence of the suspension vertical stiffness on both the frequency-weighted and unweighted vertical and pitch rms accelerations. Increase in the vertical stiffness causes higher pitch and vertical mode resonance frequencies, which resulted in higher frequency-weighted and unweighted vertical and pitch rms accelerations. Same effect can be observed on the longitudinal rms acceleration due to coupling between the longitudinal and pitch dynamics. The influence of variations in the vertical stiffness, however, is negligible on the roll and lateral accelerations, suggesting relatively weak coupling of the vertical mode with roll and lateral modes of the vehicle. While the lateral stiffness variations show only minimal effect on the roll responses, the un-weighted lateral rms acceleration is strongly affected by both the torsional and lateral suspension stiffness suggesting greater coupling between the roll and lateral responses of the vehicle. Reductions in both the lateral and torsional stiffness yield relatively higher magnitude of the weighted lateral acceleration, which may be partly attributed to reduced roll and lateral mode frequencies, below $1 \mathrm{~Hz}$, where the effect of $W_{d}$-weighting is greater. The roll response is mostly affected by the torsional stiffness, where a reduction in the torsional stiffness results in higher roll acceleration.

The torsio-elastic suspension provides only light damping, which may not yield important influences on the ride vibration responses. However, the frequency-weighted and unweighted vertical, longitudinal, and pitch accelerations tend to increase with lower vertical damping of the 
torsio-elastic suspension. The roll acceleration response is only slightly affected by the torsional and lateral damping coefficients. The results obtained in terms of vibration total value, $a_{v}$, suggest that a suspension design with lower vertical stiffness and higher lateral and torsional stiffness, and higher vertical damping would yield lower overall weighted rms acceleration, while the effects of lateral and torsional damping are relatively small.

The kinematic effect of the suspension mechanism is investigated from the responses sensitivity to variation in the suspension linkage length. The results (Table 4) suggest that an increase in $L_{0}$ yields lower roll and lateral responses, which is partly attributed to lower effective-roll stiffness, while the effects on frequency-weighted and unweighted vertical, longitudinal, and pitch responses are relatively small. A $25 \%$ increase in $L_{0}$ results in nearly $12 \%$ reduction in the vibration total value.

Apart from the suspension parameters, forestry skidders are invariably subject to high load variations during a work cycle, which could greatly affect the ride vibration responses. The ride responses of loaded vehicle are thus obtained in terms of unweighted and frequency weighted rms acceleration responses for both the conventional and suspended vehicle models. The loaded condition is realized by increasing the vehicle sprung mass by $50 \%$ of the nominal mass presented in Table 1. The results are compared with those of the unloaded vehicle models in Table 5. The results show that the loaded unsuspended vehicle yields considerably higher acceleration responses compared to the unloaded vehicle along all the axes, except in the longitudinal direction. In particular, the weighted vertical, lateral, pitch and roll rms accelerations of the loaded vehicle are nearly $25 \%, 15 \%, 55 \%$ and $110 \%$ higher than those of the unloaded vehicle. The suspended vehicle, however, exhibits significantly lower sensitivity to variations in the load, as seen in Table 5. The unweighted responses of the loaded suspended vehicle are either comparable or slightly lower than those of the unloaded vehicle along all the translational and rotational axes. The weighted responses of the loaded suspended vehicle along the translational axes are also lower than those of the unloaded vehicle. The frequency-weighted roll and pitch responses of the loaded vehicle, however, are nearly $25 \%$ greater than those of the unloaded vehicle. This is caused by lower pitch and roll resonance frequencies of the loaded vehicle and contributions of the $W_{e}$-weighting. The results clearly suggest that the torsio-elastic suspension is not greatly sensitive to variations in the load, when WBV exposure of operator is concerned.

\section{TABLE 5 about here}

\section{Conclusions}

This study developed a comprehensive off-road vehicle ride dynamics model integrating a threedimensional tire-terrain interaction model, which can be effectively and efficiently applied to both suspended and unsuspended vehicles. The tire-terrain interaction model comprised an adaptive radial representation for characterizing the resultant vertical and longitudinal forces within the contact patch, and a lateral dynamic model based on the side-slip theory together with the tire-lag. The forestry terrain was described by a regression roughness model of an equivalent undeformable terrain that was estimated from the field-measured responses of a conventional unsuspended skidder. The roughness profiles of the two parallel tracks of the terrain were synthesized assuming a coherence function between the random roughness of the two tracks. The synthesized roughness characteristics revealed peak roll excitation due to terrain in the order of 6 degrees. 
The model responses were subsequently evaluated in terms of PSD of accelerations, and weighted and un-weighted rms accelerations along the vertical, fore-aft, lateral roll and pitch axes for both the unsuspended and suspended vehicle models. The validity of the models was demonstrated by comparing the response spectra and overall rms accelerations with the reported field-measured responses for the same vehicle with and without suspension. Both the conventional and suspended vehicle models responses agreed very well with the measured responses in all the directions considered. Good agreement was also evident in the longitudinal and lateral axis for both the vehicle models suggesting that the three-dimensional tire model can provide good prediction of the vehicle ride responses along all the translational and rotational axes. The validated vehicle ride dynamics models could thus serve as important tools for suspension design and assessments of WBV exposure of drivers of off-road vehicles. Based on the developed off-road vehicle ride dynamics model, the use of a rear-axle torsio-elastic suspension resulted in nearly $38 \%$ reduction in the vibration total value. Furthermore, the suspension revealed only little sensitivity to variations in the vehicle load.

\section{References}

1. Gillespie, T.D., 1985, Heavy truck ride, SAE Paper 850001, PA, USA.

2. Su, H., Rakheja, S. and Sankar, T.S., 1992, Random response analysis of a non-linear vehicle suspension with tunable shock absorber, Mechanical Systems and Signal Processing, 6, pp. 363-381.

3. Priyandoko, G., Mailah, M. and Jamaluddin, H., 2009, Vehicle active suspension system using skyhook adapative neuro active force control, Mechanical Systems and Signal Processing, 23, pp. 855-868.

4. Cao, D., Song, X. and Ahmadian, M., 2011, Editors' perspectives: road vehicle suspension design, dynamics, and control, Vehicle System Dynamics, 49, pp. 3-28.

5. ISO 2631-1, 1997, Mechanical vibration and shock-evaluation of human exposure to wholebody vibration - part 1: general requirements, ISO, Geneva, Switzerland.

6. Griffin, M.J., 2007, Discomfort from feeling vehicle vibration, Vehicle System Dynamics, 45, pp. 679-698.

7. Rakheja, S., Dong R.G., Patra, S., Boileau, P.-E., Marcotte, P. and Warren, C., 2010, Biodynamics of the human body under whole-body vibration: synthesis of the reported data, International Journal of Industrial Ergonomics, 40, pp. 710-732.

8. Seidel, H., 2005, On the relationship between whole body vibration exposure and spinal health risk, Industrial Health, 43, pp. 361-377.

9. Bovenzi, M., Rui, F., Negro, C., D’Agostin, F., Angotzi, G., Bianchi, S., Bramanti, L., Festa, G., Gatti, S., Pinto, L., Rondina, L. and Stacchini, N., 2006, An epidemiological study of low back pain in professional drivers, Journal of Sound and Vibration, 298, pp. 514-539.

10. Cation, S., Jack, R.J., Dickey, J.P., Lee-Shee, N. and Oliver, M., 2008, Six degree of freedom whole-body vibration during forestry skidder operations, International Journal of Industrial Ergonomics, 38, pp. 739-757.

11. Neitzel, R. and Yost, M., 2002, Task-based assessment of occupational vibration and noise exposure in forestry workers. American Industrial Hygiene Association (AIHA) Journal, 63, pp. 617-627. 
12. European Committee for Standardization (CEN), 2003, Mechanical vibration. Measurement and evaluation of occupational exposure to whole-body vibration with reference to health. Practical guidance (Standard No. EN 14253:2003). Brussels, Belgium: CEN.

13. Tiemessen, I.J., Hulshof, C.T.J. and Frings-Dresen, M.H.W., 2007, An overview of strategies to reduce whole-body vibration exposure on drivers: a systematic review, International Journal of Industrial Ergonomics, 37, pp. 245-256.

14. Rehn, B., Olofsson, B., Lundstrom, R., Nilsson, L., Liljelind, I. and Jarvholm, B., 2005, Variation in exposure to whole-body vibration for operators of forwarder vehicles - aspects on measurement strategies and prevention, International Journal of Industrial Ergonomics, 35, pp. 831-842.

15. Donati, P., 2002, Survey of technical preventative measures to reduce whole-body vibration effects when designing mobile machinery, Journal of Sound and Vibration, 251, pp. 169-183.

16. Ma, X.Q., Rakheja, S. and Su, C-Y., 2008, Damping requirement of a suspension seat subject to low frequency vehicle vibration and shock, International Journal of Vehicle Design, 47, pp. 133-156.

17. Ma, X.Q., Rakheja, S. and Su, C-Y., 2008, Synthesis of a semi-active suspension seat for attenuation of whole-body vibration and shock, International Journal of Vehicle Design, 47, pp. 157-175.

18. Boulanger, P., Lemerle, P. and Poirot, R., 2002, A simplified method to design a suspension cab for counterbalance trucks, Journal of Sound and Vibration, 253, pp. 283-293.

19. Ahmadian, M. and Patrico, P.S., 2004, Effect of panhard rod cab suspensions on heavy truck ride measurements, SAE Transactions, 113, pp. 551-559.

20. Rakheja, S., Mandapuram, S. and Dong, R.G., 2008, Energy absorption of seated occupants exposed to horizontal vibration and role of back support condition, Industrial Health, 46, pp. 550-566.

21. Lehtonen, T. J. and Juhala, M., 2005, Predicting the ride behavior of a suspended agricultural tractor, International Journal of System Modeling and Testing, 1, pp. 131-142.

22. Uys, P.E., Els, P.S. and Thoresson, M., 2006, Suspension setting for optimal ride comfort of off-road vehicles travelling on roads with different roughness and speeds, Journal of Terramechanics, 44, pp. 163-175.

23. Mazhei A., Uspenskiy, A., Ermalenok V., 2006, Dynamic analysis of the hydro-pneumatic front axle suspension of agriculture tractor, SAE Paper 2006-01-3526, PA, USA.

24. Hansson, P-A., 2002, Working space requirement for an agricultural tractor axle suspension, Biosystems Engineering, 81, pp. 57-71.

25. Rehnberg, A. and Drugge, L., 2008, Ride comfort simulation of a wheel loader with suspended axles, International journal of vehicle system modeling and testing, 3, pp. 168188.

26. Pazooki, A., Cao, D., Rakheja, S. and Boileau, P.-E., 2011, Ride dynamic evaluations and design optimization of a torsio-elastic off-road vehicle suspension, Vehicle System Dynamics, 49, pp. 1455-1476.

27. Cao, D., Rakheja, S. and Su, C.-Y., 2010, Roll- and pitch-plane coupled hydro-pneumatic suspension. Part 1: feasibility analysis and suspension properties, Vehicle System Dynamics, 48, pp. 361-386.

28. Cao, D., Rakheja, S. and Su, C.-Y., 2010, Roll- and pitch-plane coupled hydro-pneumatic suspension. Part 2: dynamic response analysis, Vehicle System Dynamics, 48, pp. 507-528. 
29. Andersson, P.B.U. and Kropp, W., 2008, Time domain contact model for tyre/road interaction including nonlinear contact stiffness due to small-scale roughness, Journal of Sound and Vibration, 318, pp. 296-312.

30. Lescoe, R., El-Gindy, M., Koudela, K., Oijer, F., Trivedi, M. and Johansson, I., 2010, Tiresoil modeling using finite element analysis and smooth practical hydrodynamics techniques, Proceedings of ASME International Design Engineering Technical Conference, DETC201028002, Montreal, Canada.

31. Crolla, D.A., Horton, D.N.L. and Stayner, R.M., 1990, Effect of tyre modeling on tractor ride vibration prediction, Journal of Agricultural Engineering, 47, pp. 55-77.

32. Rakheja, S., Wang, K., Bhat, R.B. and Boileau, P.-E., 2002, Enhancement of ride vibration environment of tracked snowplows: vehicle modeling and analysis, International Journal of Vehicle Design, 30, pp. 193-222.

33. Xiding, Q., Jude, L. and Yongxin, M., 1993, A modified point contact tire model for the simulation of vehicle ride quality, Journal of Terramechanics, 30, pp. 133-141.

34. Wang, K., 2000, Dynamic analysis of a tracked snowplowing vehicle and assessment of ride quality, Master Thesis, Concordia University, Montreal, Canada.

35. Crolla, D.A. and El-Razaz, A.S.A., 1987, A review of the combined lateral force generation of tires on deformable surfaces. Journal of Terramechanics, 24, pp. 25-82.

36. Wong, J.Y., 2002, Theory of ground vehicles, 4th Edition, John Wiley \& Sons, New York, USA.

37. Logdanoff, J,L, Kozin, F. and Cote, L.J., 1996, Atlas of off-road ground roughness PSDs and report on data acquisition techniques, ATAC Components Research and Development Laboratories Technical Report No.9387 (LL109), U.S. Army Tank-Automotive Center, Warren, MI, USA.

38. Hac, A., 1987, Adaptive control of vehicle suspension, Vehicle System Dynamics, 16, pp. 57-74.

39. Bendat, J. S. and Piersol, A.G., 2000, Random data analysis and measurement procedures, 3rd Edition, John Wiley \& Sons, New York, USA.

40. Bogsjo, K., 2008, Coherence of road roughness in left and right wheel-path, Vehicle System Dynamics, 46(supp), pp. 599-609.

41. Yonglin, Z. and Jiafan, Z., 2006, Numerical simulation of stochastic road process using white noise filtration, Mechanical Systems and Signal Processing, 20, pp. 363-372.

42. Welch, P.D., 1967, The use of fast fourier transform for the estimation of power spectra: a method based on time averaging over short, modified periodograms, IEEE Trans. Audio Electroacoustics, 15, pp. 70-73.

43. FERIC/FP Innovations, 1979, The forestry engineering research institute of Canada. Montreal, Canada.

\section{Nomenclature}

$m_{s}, m_{s}^{\prime} \quad$ Mass of the un-suspended and suspended vehicles

$I_{Y Y S} \quad$ Pitch mass moments of inertia of the un-suspended vehicle

$I_{Y Y S}^{\prime} \quad$ Pitch mass moments of inertia of the suspended vehicle sprung mass

$I_{X X S}, I_{X X S}^{\prime} \quad$ Roll mass moments of inertia of the un-suspended and suspended vehicles

WB1, WB2 Longitudinal coordinates of the front and rear axles with respect to vehicle cg 
$m_{u r} \quad$ Real axle mass

$m_{3}, m_{4} \quad$ Right- and left- suspension linkage masses

$M \quad$ Total mass of the suspended vehicle

$I_{3}, I_{4}, I_{r} \quad$ Rear-axle, right-and left- suspension linkage roll mass moment of inertia

$c_{y}, c_{z}, c_{t} \quad$ Lateral, vertical, and torsional damping coefficients of the suspension

$k_{y}, k_{z}, k_{t} \quad$ Lateral, vertical, and torsional stiffness coefficients of the suspension

$F_{z i}, F_{z u i} \quad$ Vertical suspension forces acting on the sprung and unsprung mass $(i=3,4)$

$F_{y i}, F_{y u i} \quad$ Lateral forces acting on the sprung and unsprung mass $(i=3,4)$

$M_{\varphi i s}, M_{\varphi i u} \quad$ Roll moments acting on the sprung and unsprung mass $(i=3,4)$

Table 1: Simulation parameters.

Table 2: Comparisons of frequency-weighted and unweighted rms acceleration values $\left(\mathrm{m} / \mathrm{s}^{2}\right)$ of the unsuspended vehicle model with the corresponding measured values.

Table 3: Comparisons of the weighted and unweighted rms acceleration values $\left(\mathrm{m} / \mathrm{s}^{2}\right)$ of the suspended vehicle model with the corresponding measured values.

Table 4: Influence of variations in the torsio-elastic suspension stiffness and damping properties on the weighted and unweighted rms acceleration responses of the model.

Table 5: Influence of vehicle load on the weighted and unweighted rms acceleration responses of the unsuspended and suspended vehicle models. 
Fig. 1: Adaptive foot-print radial tire model.

Fig. 2: (a) Wheel-terrain contact patch; and (b) Circle-line interaction representation.

Fig. 3: Tire lateral ride dynamic model consisting of linear spring and damper in series.

Fig. 4: Pitch- and roll-plane representations of an unsuspended skidder: (a) Pitch-plane; and (b) Roll-plane, (front view)

Fig. 5: Schematic representation of the 14-DOF suspended vehicle model: (a) roll plane; (b) pitch plane; and (c) torsio-elastic suspension linkage mechanism.

Fig. 6: Comparison of the roughness profile with that estimated from model proposed by Hac [38].

Fig. 7: Comparison of the coherence values obtained from Eq. (33) with that approximated by fractional system function.

Fig. 8: Flowchart of the proposed method to find the time series of two tracks profiles.

Fig. 9: Time histories of roughness of the (a) left track; and (b) right track $(U=5 \mathrm{~km} / \mathrm{h})$.

Fig. 10: Coherence of the two track profiles compared with the target coherence.

Fig. 11: Roll displacement (a) time-history; and (b) PSD spectrum.

Fig. 12: Comparisons of acceleration PSD responses of the conventional vehicle model with those of the measured data.

Fig. 13: Comparisons of acceleration PSD responses of the suspended vehicle model with those of the measured data. 
Table 1: Simulation parameters.

\begin{tabular}{cr|cr}
\hline Parameter & value & Parameter & \multicolumn{1}{c}{ value } \\
\hline$m_{s}^{\prime}$ & $8616 \mathrm{~kg}$ & $k_{z}$ & $185 \mathrm{kN} / \mathrm{m}$ \\
$m_{s}$ & $9662 \mathrm{~kg}$ & $k_{y}$ & $185 \mathrm{kN} / \mathrm{m}$ \\
$m_{3}$ & $42.6 \mathrm{~kg}$ & $k_{t}$ & $125 \mathrm{kNm} / \mathrm{rad}$ \\
$m_{4}$ & $42.6 \mathrm{~kg}$ & $c_{z}$ & $4000 \mathrm{Nm} . \mathrm{s} / \mathrm{rad}$ \\
$m_{u r}$ & $1500 \mathrm{~kg}$ & $c_{y}$ & $4000 \mathrm{~N} . \mathrm{s} / \mathrm{m}$ \\
$I_{X X S}^{\prime}$ & $10495 \mathrm{~kg} \cdot \mathrm{m}^{2}$ & $c_{t}$ & $3500 \mathrm{~N} . \mathrm{s} / \mathrm{m}$ \\
$I_{Y Y S}^{\prime}$ & $16353 \mathrm{~kg} \cdot \mathrm{m}^{2}$ & $K$ & $94.5 \mathrm{kN} / \mathrm{rad}$ \\
$I_{3}$ & $3500 \mathrm{~kg} \cdot \mathrm{m}^{2}$ & $C$ & $2000 \mathrm{~N} . \mathrm{s} / \mathrm{m}$ \\
$I_{4}$ & $3500 \mathrm{~kg} \cdot \mathrm{m}^{2}$ & $\sigma$ & $0.40 \mathrm{~m}$ \\
$h^{\prime}$ & $0.43 \mathrm{~m}$ & $L_{0}$ & $0.16 \mathrm{~m}$ \\
$W B_{1}$ & $1.23 \mathrm{~m}$ & $h$ & $0.60 \mathrm{~m}$ \\
$W B_{2}$ & $1.90 \mathrm{~m}$ & $l_{x}$ & $0.29 \mathrm{~m}$ \\
$2 T$ & $2.50 \mathrm{~m}$ & $\delta_{s t}$ & $0.20 \mathrm{~m}$ \\
$R_{w}$ & $0.80 \mathrm{~m}$ & $K_{T y}$ & $256 \mathrm{kN} / \mathrm{m}$ \\
$C_{\alpha}$ & $102 \mathrm{kN} / \mathrm{m}$ & $h_{1}$ & $0.21 \mathrm{~m}$ \\
\hline
\end{tabular}

Table 2: Comparisons of frequency-weighted and unweighted $\mathrm{rms}$ acceleration values $\left(\mathrm{m} / \mathrm{s}^{2}\right)$ of the unsuspended vehicle model with the corresponding measured values.

\begin{tabular}{|c|c|c|c|c|c|c|c|c|}
\hline \multicolumn{2}{|r|}{ Axis } & Bounce & Longitudinal & Lateral & Pitch & Roll & $a_{v}$ & $A(8)$ \\
\hline \multirow{3}{*}{ 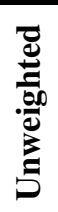 } & Model & 1.97 & 1.39 & 1.53 & 0.67 & 1.00 & & \\
\hline & Measured & 1.83 & 1.59 & 1.79 & 0.70 & 1.10 & & \\
\hline & Deviation (\%) & 7.6 & -12.6 & -14.6 & -4.5 & -9.1 & & \\
\hline \multirow{3}{*}{ 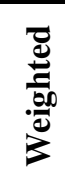 } & Model & 1.20 & 1.24 & 1.34 & 0.44 & 0.69 & 2.82 & 2.00 \\
\hline & Measured & 1.12 & 1.43 & 1.52 & 0.46 & 0.75 & 3.13 & 2.22 \\
\hline & Deviation (\%) & 7.1 & -13.3 & -11.8 & -4.3 & -8.0 & -9.9 & -9.9 \\
\hline
\end{tabular}

Table 3: Comparisons of the weighted and unweighted rms acceleration values $\left(\mathrm{m} / \mathrm{s}^{2}\right)$ of the suspended vehicle model with the corresponding measured values.

\begin{tabular}{|c|c|c|c|c|c|c|c|c|}
\hline \multicolumn{2}{|r|}{ Axis } & Bounce & Longitudinal & Lateral & Pitch & Roll & $a_{v}$ & $A(8)$ \\
\hline \multirow{3}{*}{ 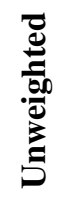 } & Model & 1.05 & 1.00 & 1.38 & 0.85 & 0.96 & & \\
\hline & Measured & 1.00 & 0.89 & 1.30 & 0.82 & 0.87 & & \\
\hline & Deviation (\%) & 5.0 & 12.4 & 6.2 & 3.6 & 10.3 & & \\
\hline \multirow{3}{*}{ 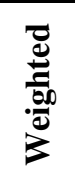 } & Model & 0.65 & 0.89 & 1.17 & 0.44 & 0.48 & 2.16 & 1.53 \\
\hline & Measured & 0.62 & 0.78 & 1.07 & 0.43 & 0.44 & 1.95 & 1.38 \\
\hline & Deviation (\%) & 4.8 & 14.1 & 9.3 & 2.3 & 9.1 & 10.8 & 10.8 \\
\hline
\end{tabular}


Table 4: Influence of variations in the torsio-elastic suspension stiffness and damping properties on the weighted and unweighted rms acceleration responses of the model.

\begin{tabular}{|c|c|c|c|c|c|c|c|c|c|c|c|c|}
\hline \multirow{2}{*}{\multicolumn{2}{|c|}{$\begin{array}{c}\text { Parameter } \\
\mathrm{S}\end{array}$}} & \multicolumn{5}{|c|}{ Weighted rms acceleration } & \multirow[b]{2}{*}{$a_{v}$} & \multicolumn{5}{|c|}{ Unweighted rms acceleration } \\
\hline & & $z$ & $x$ & $y$ & $\theta$ & $\phi$ & & $z$ & $x$ & $y$ & $\theta$ & $\phi$ \\
\hline \multicolumn{2}{|c|}{$\begin{array}{l}\text { Nominal } \\
\text { value }\end{array}$} & 0.65 & 0.89 & 1.17 & 0.44 & 0.48 & 2.16 & 1.05 & 1.00 & 1.38 & 0.85 & 0.96 \\
\hline \multirow{2}{*}{$k_{z}$} & $-50 \%$ & 0.61 & 0.85 & 1.17 & 0.40 & 0.48 & 2.11 & 0.90 & 0.90 & 1.38 & 0.73 & 0.97 \\
\hline & $+50 \%$ & 0.73 & 0.92 & 1.17 & 0.48 & 0.48 & 2.20 & 1.25 & 1.16 & 1.38 & 1.02 & 0.95 \\
\hline \multirow{2}{*}{$k_{y}$} & $-50 \%$ & 0.65 & 0.89 & 1.26 & 0.44 & 0.47 & 2.28 & 1.05 & 1.01 & 1.32 & 0.85 & 0.94 \\
\hline & $+50 \%$ & 0.65 & 0.89 & 1.10 & 0.44 & 0.49 & 2.07 & 1.05 & 1.01 & 1.43 & 0.85 & 0.99 \\
\hline \multirow{2}{*}{$k_{t}$} & $-50 \%$ & 0.65 & 0.89 & 1.21 & 0.44 & 0.51 & 2.23 & 1.05 & 1.01 & 1.34 & 0.85 & 1.09 \\
\hline & $+50 \%$ & 0.65 & 0.89 & 1.14 & 0.44 & 0.43 & 2.11 & 1.05 & 1.01 & 1.41 & 0.85 & 0.81 \\
\hline \multirow[b]{2}{*}{$c_{z}$} & $-50 \%$ & 0.66 & 0.96 & 1.17 & 0.47 & 0.48 & 2.22 & 1.17 & 1.12 & 1.38 & 0.97 & 0.96 \\
\hline & $+50 \%$ & 0.65 & 0.83 & 1.17 & 0.41 & 0.48 & 2.11 & 1.02 & 0.94 & 1.38 & 0.77 & 0.96 \\
\hline \multirow[b]{2}{*}{$c_{y}$} & $-50 \%$ & 0.65 & 0.89 & 1.18 & 0.44 & 0.49 & 2.17 & 1.05 & 1.01 & 1.43 & 0.85 & 0.98 \\
\hline & $+50 \%$ & 0.65 & 0.89 & 1.16 & 0.44 & 0.47 & 2.15 & 1.05 & 1.01 & 1.36 & 0.85 & 0.95 \\
\hline \multirow[b]{2}{*}{$c_{t}$} & $-50 \%$ & 0.65 & 0.89 & 1.17 & 0.44 & 0.49 & 2.16 & 1.05 & 1.01 & 1.40 & 0.85 & 1.00 \\
\hline & $+50 \%$ & 0.65 & 0.89 & 1.17 & 0.44 & 0.47 & 2.16 & 1.05 & 1.01 & 1.37 & 0.85 & 0.96 \\
\hline \multirow{2}{*}{$L_{0}$} & $-25 \%$ & 0.65 & 0.89 & 1.18 & 0.44 & 0.49 & 2.17 & 1.05 & 1.00 & 1.38 & 0.84 & 0.96 \\
\hline & $+25 \%$ & 0.63 & 0.90 & 0.92 & 0.48 & 0.37 & 1.91 & 1.02 & 1.03 & 1.13 & 0.88 & 0.78 \\
\hline
\end{tabular}

Table 5: Influence of vehicle load on the weighted and unweighted rms acceleration responses of the unsuspended and suspended vehicle models.

\begin{tabular}{|c|c|c|c|c|c|c|c|c|c|c|c|c|}
\hline \multirow{2}{*}{\multicolumn{2}{|c|}{ Parameters }} & \multicolumn{5}{|c|}{ Weighted rms acceleration } & \multirow{3}{*}{$\begin{array}{c}a_{v} \\
2.82\end{array}$} & \multicolumn{5}{|c|}{ Unweighted rms acceleration } \\
\hline & & \multirow{2}{*}{$\frac{z}{1.20}$} & \multirow{2}{*}{$\frac{x}{1.24}$} & \multirow{2}{*}{$\frac{y}{1.34}$} & \multirow{2}{*}{$\frac{\theta}{0.44}$} & \multirow{2}{*}{$\frac{\phi}{0.69}$} & & \multirow{2}{*}{$\frac{z}{1.97}$} & \multirow{2}{*}{$\frac{x}{1.39}$} & \multirow{2}{*}{$\frac{y}{1.53}$} & \multirow{2}{*}{$\frac{\theta}{0.67}$} & \multirow{2}{*}{$\frac{\phi}{1.00}$} \\
\hline تֶّ & Un-loaded & & & & & & & & & & & \\
\hline के & Loaded & 1.50 & 1.06 & 1.54 & 0.68 & 1.44 & 3.02 & 2.42 & 1.20 & 2.02 & 0.96 & 1.92 \\
\hline \multirow{2}{*}{ 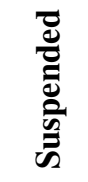 } & Un-loaded & 0.65 & 0.89 & 1.17 & 0.44 & 0.48 & 2.16 & 1.05 & 1.00 & 1.38 & 0.85 & 0.96 \\
\hline & Loaded & 0.63 & 0.82 & 1.10 & 0.54 & 0.60 & 2.05 & 1.06 & 0.96 & 1.31 & 0.78 & 0.91 \\
\hline
\end{tabular}




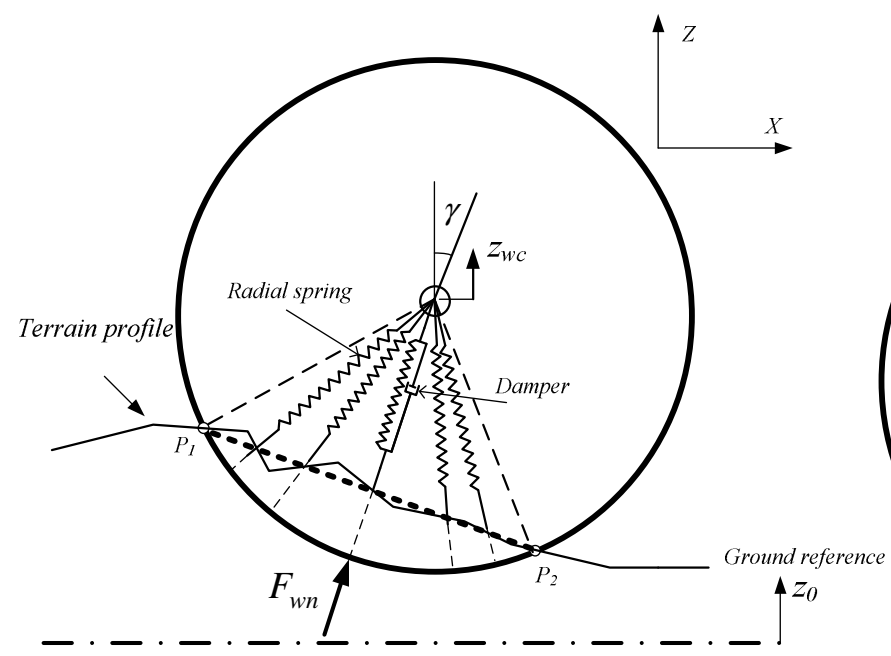

(a)

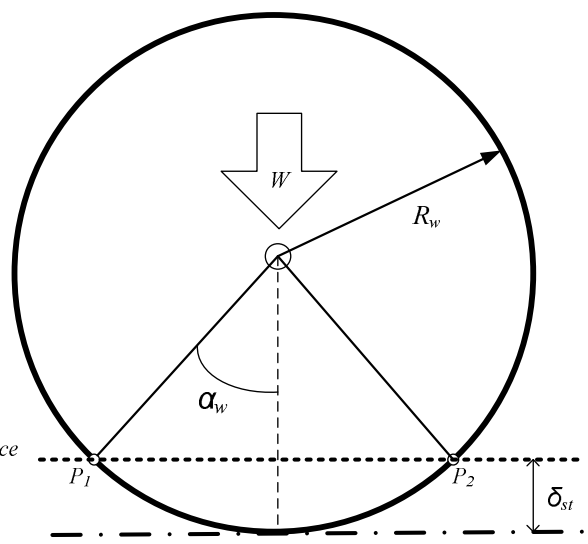

(b)

Fig. 1: Adaptive foot-print radial tire model.

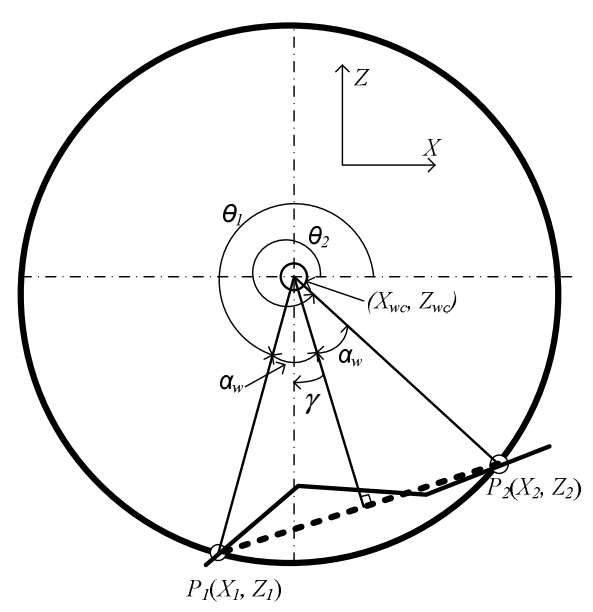

(a)

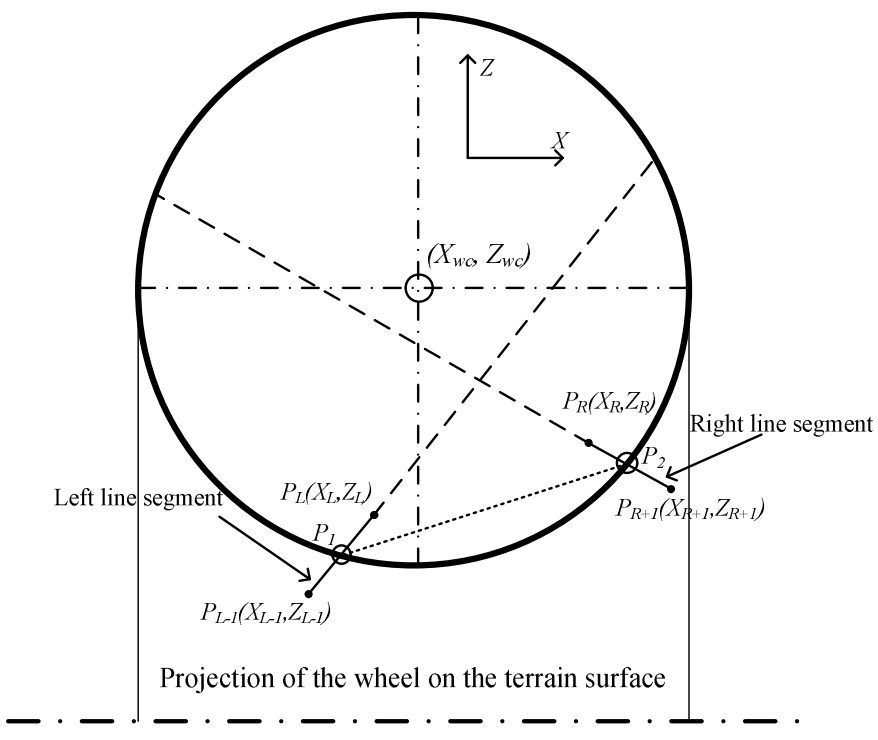

(b)

Fig. 2: (a) Wheel-terrain contact patch; and (b) Circle-line interaction representation. 


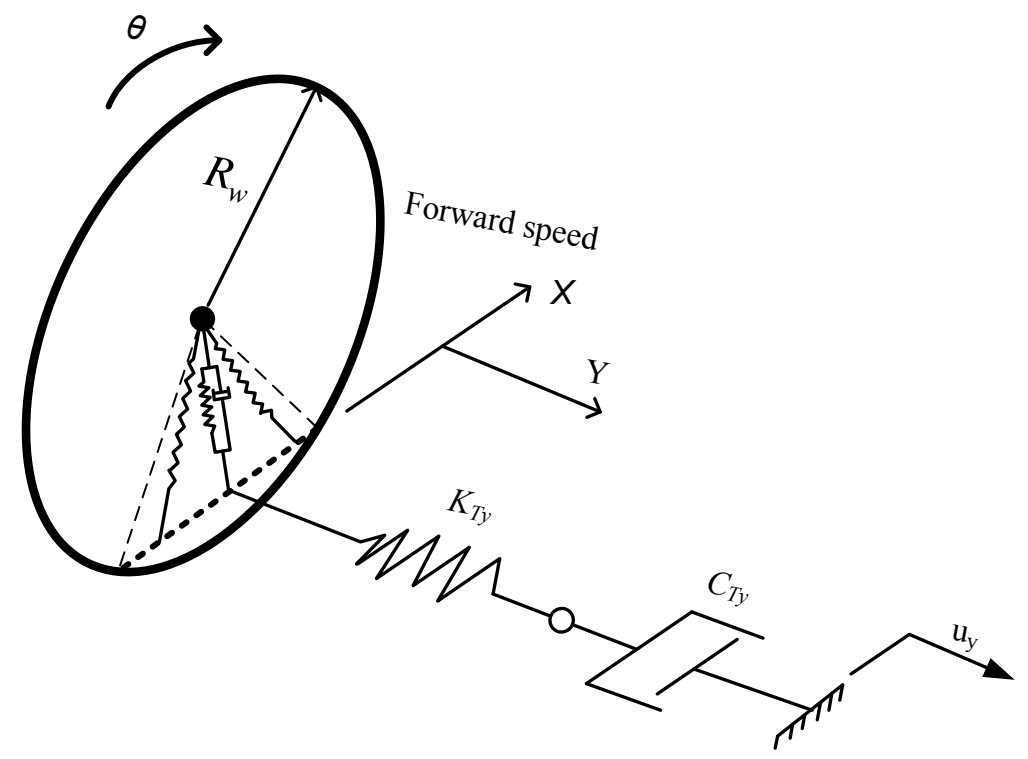

Fig. 3: Tire lateral ride dynamic model consisting of linear spring and damper in series.

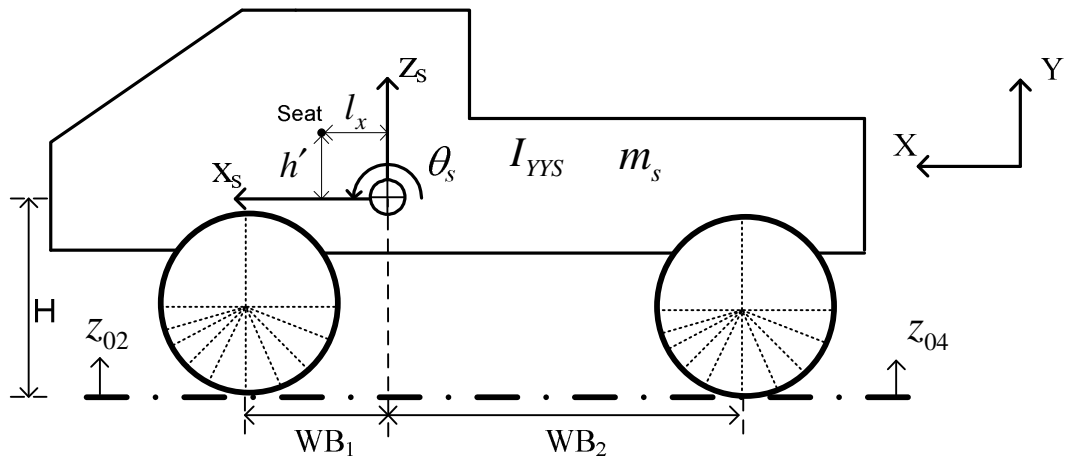

(a)

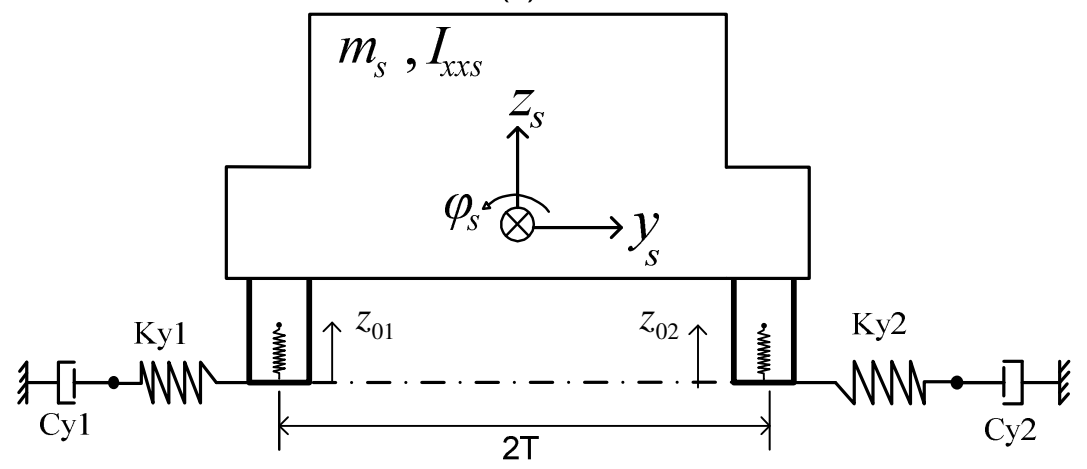

(b)

Fig. 4: Pitch- and roll-plane representations of an unsuspended skidder: (a) Pitch-plane; and (b) Roll-plane, (front view) 

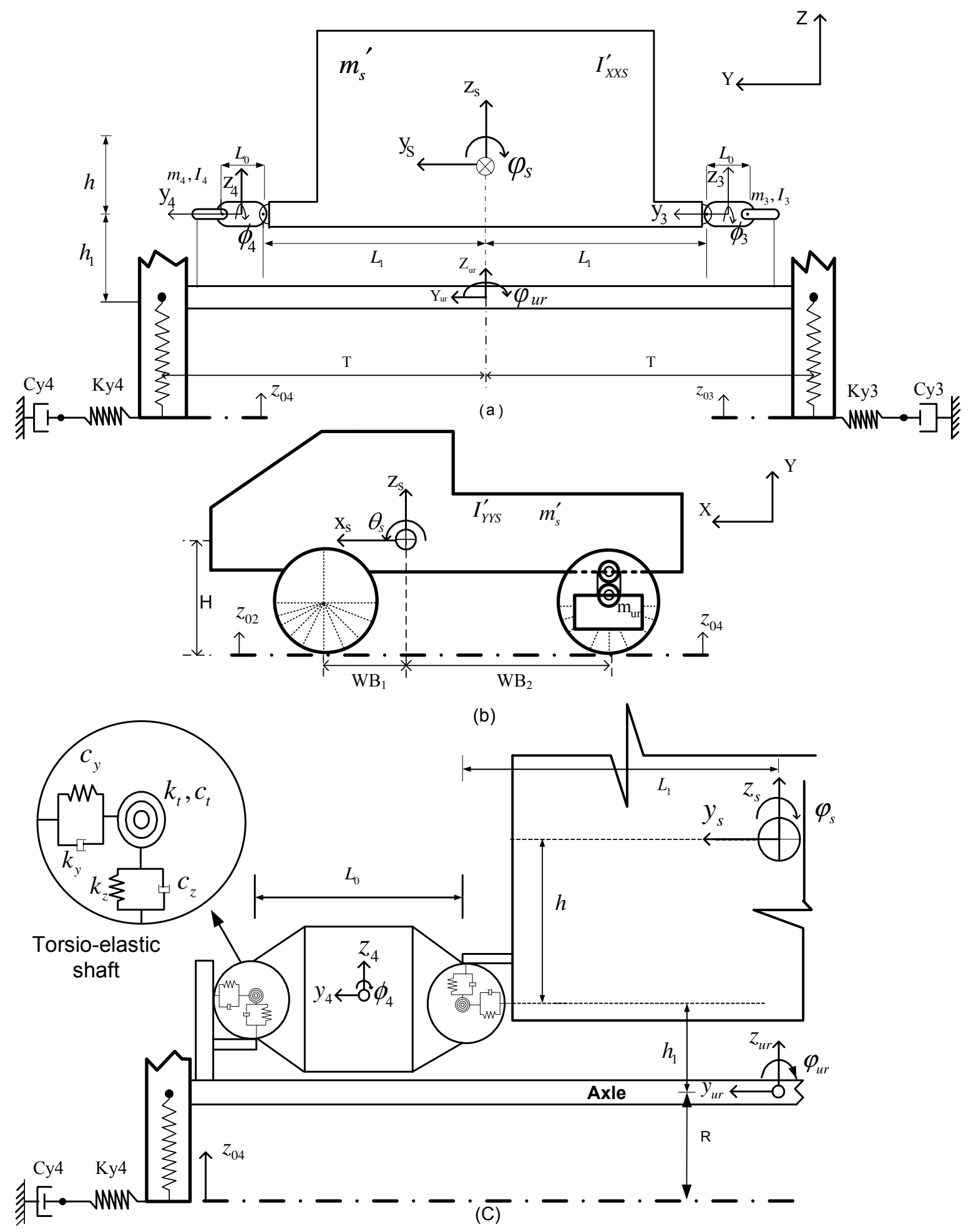

Fig. 5: Schematic representation of the 14-DOF suspended vehicle model: (a) roll plane; (b) pitch plane; and (c) torsio-elastic suspension linkage mechanism. 


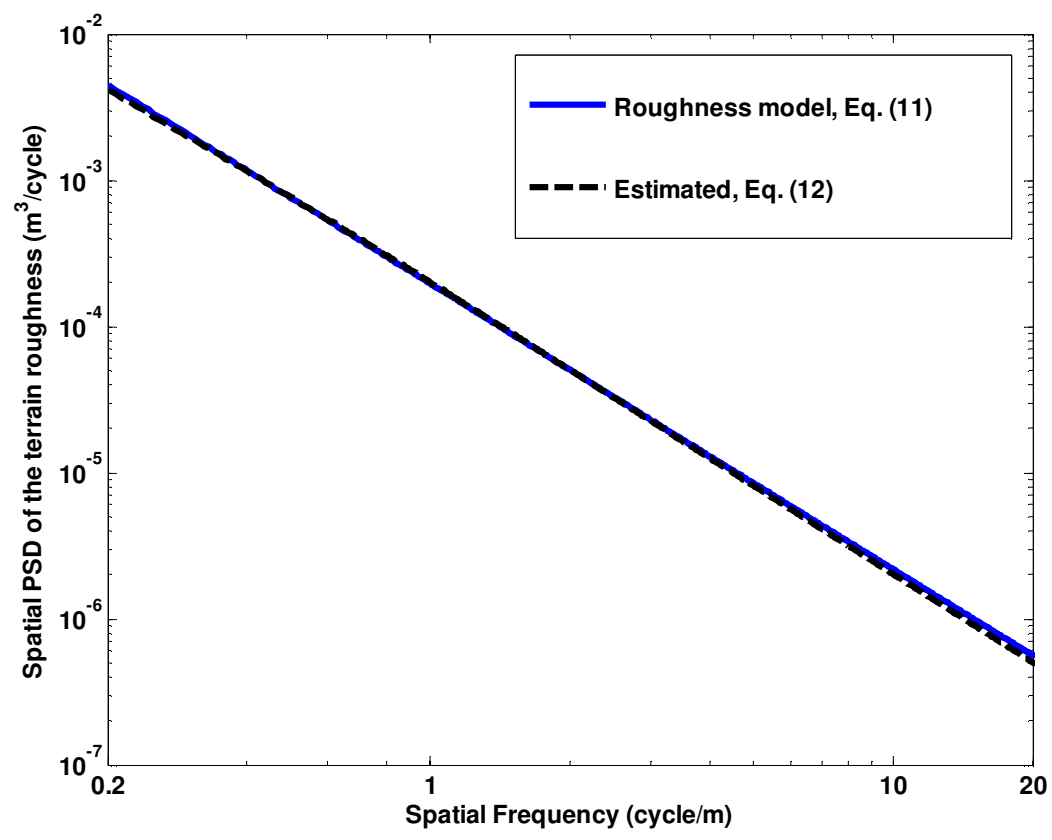

Fig. 6: Comparison of the roughness profile with that estimated from model proposed by Hac [38].

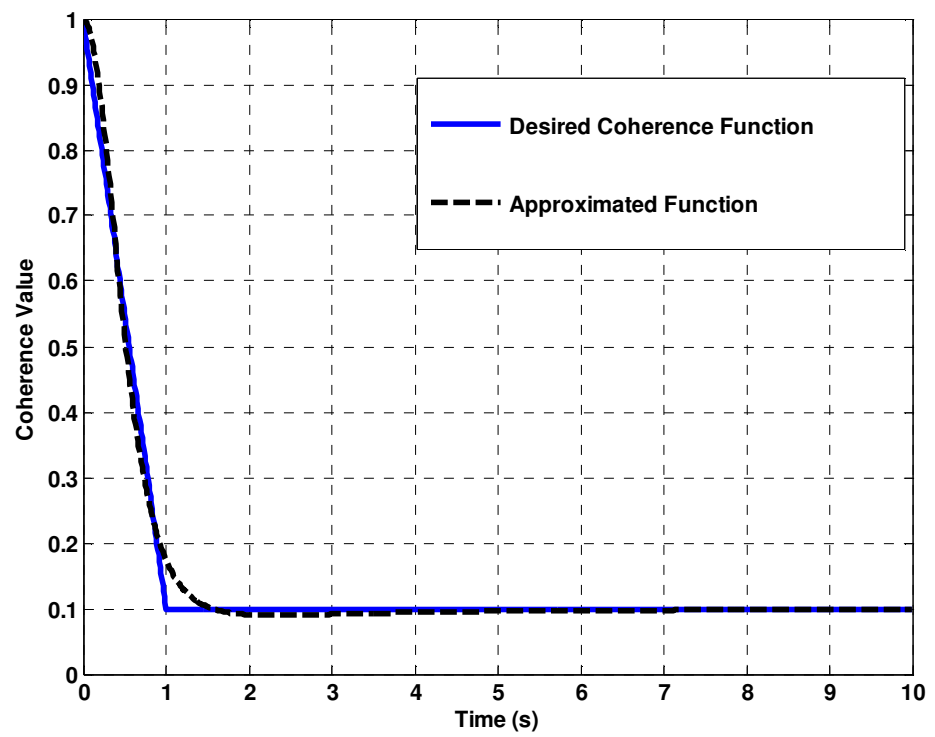

Fig. 7: Comparison of the coherence values obtained from Eq. (33) with that approximated by fractional system function. 


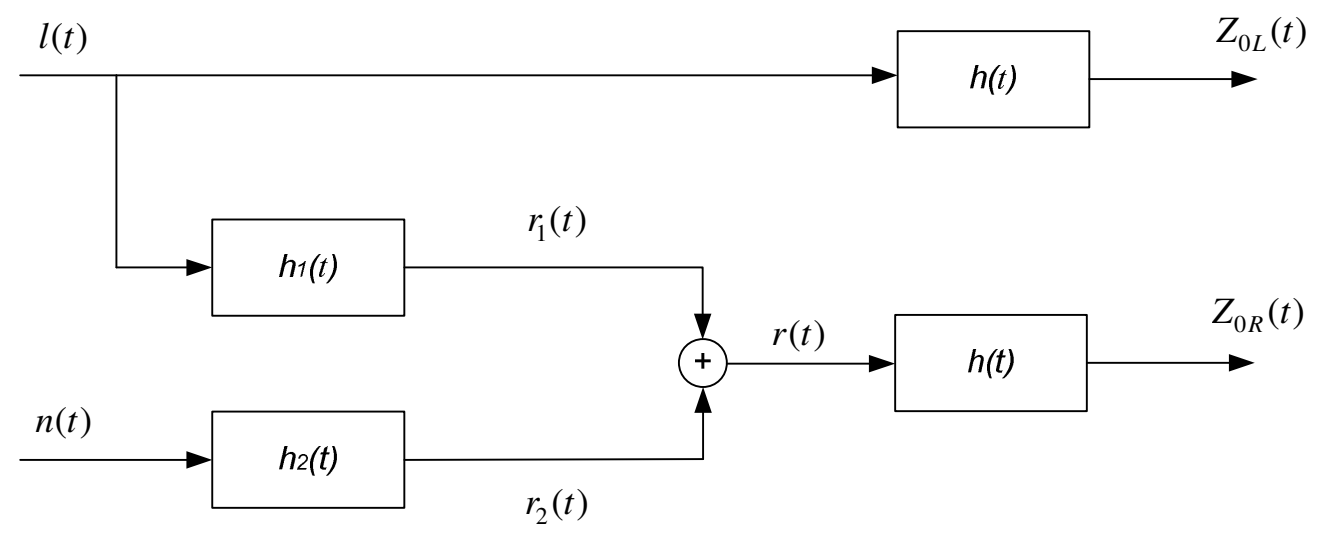

Fig. 8: Flowchart of the proposed method to find the time series of two tracks profiles.
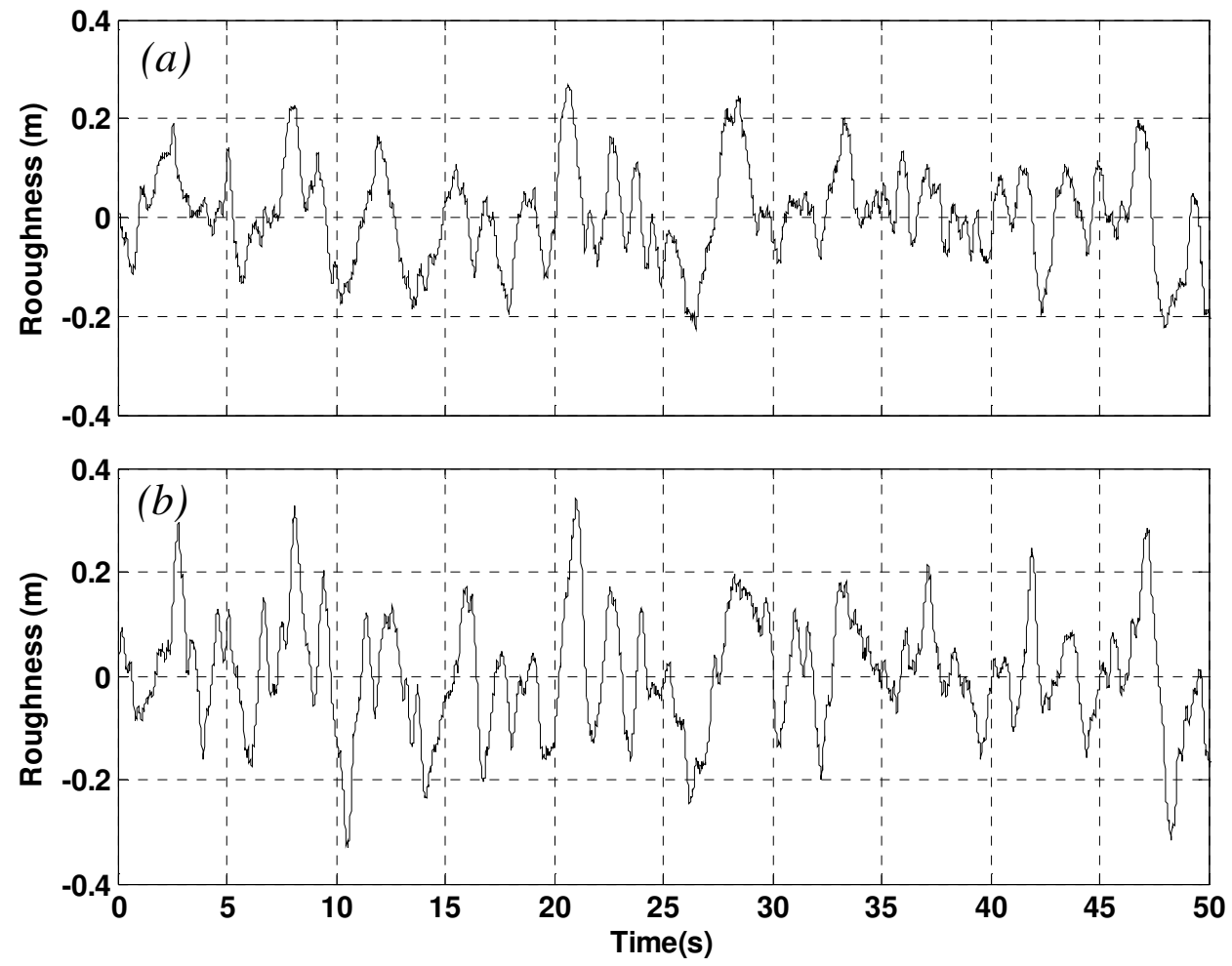

Fig. 9: Time histories of roughness of the (a) left track; and (b) right track $(U=5 \mathrm{~km} / \mathrm{h})$. 


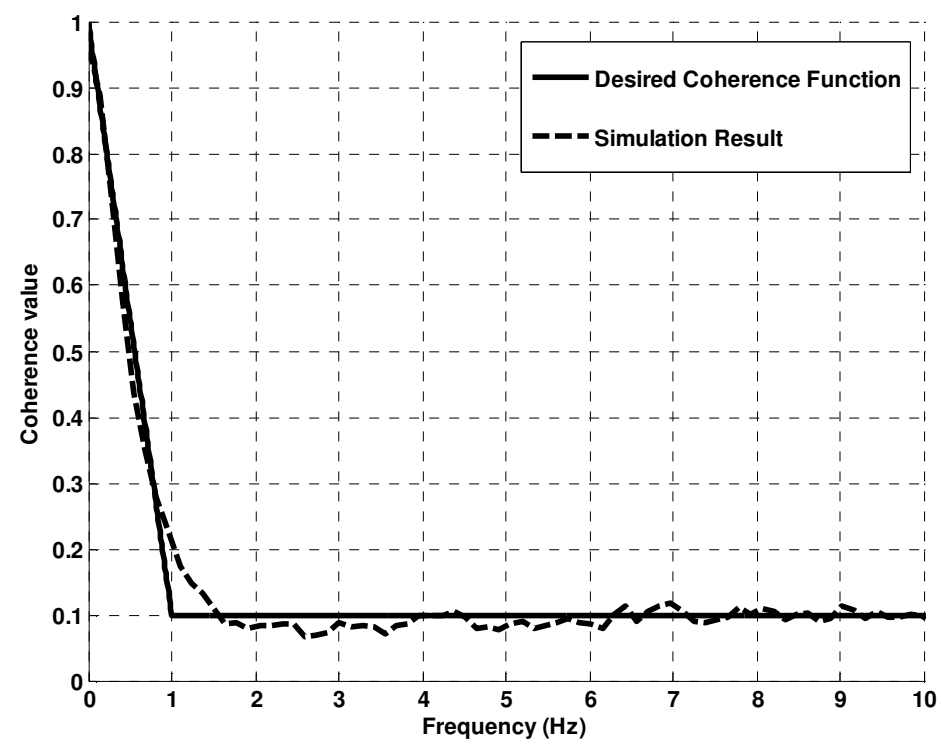

Fig. 10: Coherence of the two track profiles compared with the target coherence.
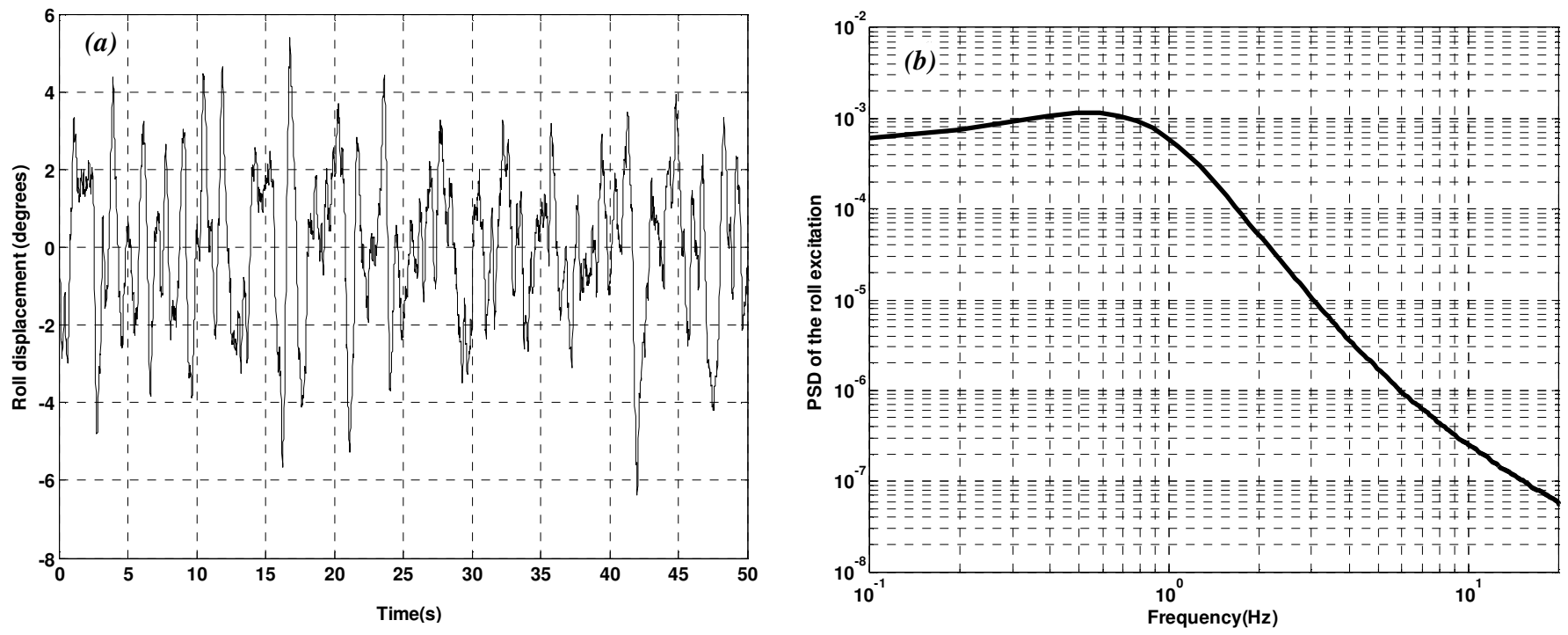

Fig. 11: Roll displacement (a) time-history; and (b) PSD spectrum. 

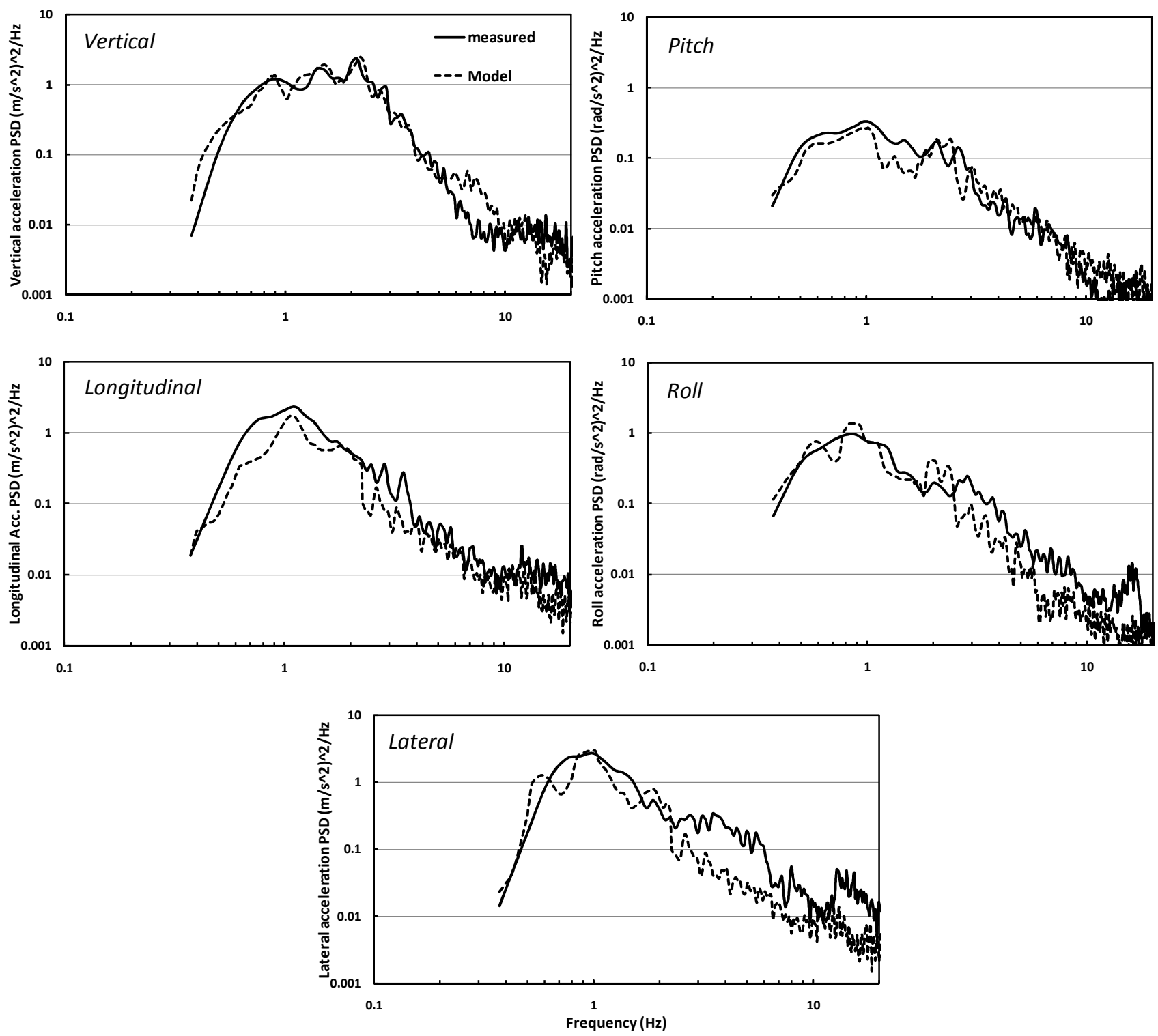

Fig. 12: Comparisons of acceleration PSD responses of the conventional vehicle model with those of the measured data. 

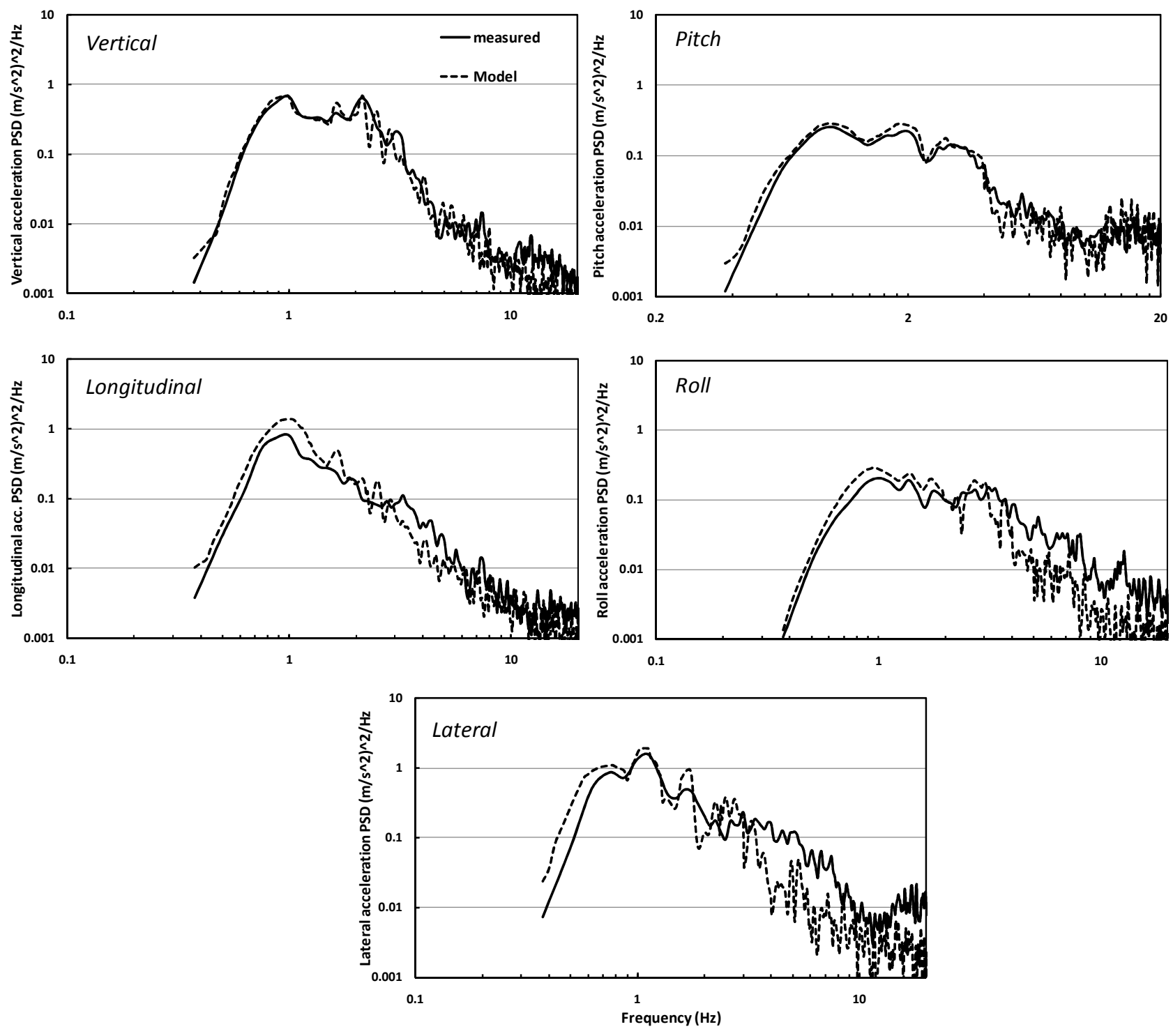

Fig. 13: Comparisons of acceleration PSD responses of the suspended vehicle model with those of the measured data. 